NASA/TM—2012-217297

\title{
Two-Dimensional Nonlinear Finite Element Analysis of CMC Microstructures
}

Subodh K. Mital

The University of Toledo, Toledo, Ohio

Robert K. Goldberg and Peter J. Bonacuse

Glenn Research Center, Cleveland, Ohio 


\section{NASA STI Program . . . in Profile}

Since its founding, NASA has been dedicated to the advancement of aeronautics and space science. The NASA Scientific and Technical Information (STI) program plays a key part in helping NASA maintain this important role.

The NASA STI Program operates under the auspices of the Agency Chief Information Officer. It collects, organizes, provides for archiving, and disseminates NASA's STI. The NASA STI program provides access to the NASA Aeronautics and Space Database and its public interface, the NASA Technical Reports Server, thus providing one of the largest collections of aeronautical and space science STI in the world. Results are published in both non-NASA channels and by NASA in the NASA STI Report Series, which includes the following report types:

- TECHNICAL PUBLICATION. Reports of completed research or a major significant phase of research that present the results of NASA programs and include extensive data or theoretical analysis. Includes compilations of significant scientific and technical data and information deemed to be of continuing reference value. NASA counterpart of peer-reviewed formal professional papers but has less stringent limitations on manuscript length and extent of graphic presentations.

- TECHNICAL MEMORANDUM. Scientific and technical findings that are preliminary or of specialized interest, e.g., quick release reports, working papers, and bibliographies that contain minimal annotation. Does not contain extensive analysis.

- CONTRACTOR REPORT. Scientific and technical findings by NASA-sponsored contractors and grantees.
- CONFERENCE PUBLICATION. Collected papers from scientific and technical conferences, symposia, seminars, or other meetings sponsored or cosponsored by NASA.

- SPECIAL PUBLICATION. Scientific, technical, or historical information from NASA programs, projects, and missions, often concerned with subjects having substantial public interest.

- TECHNICAL TRANSLATION. Englishlanguage translations of foreign scientific and technical material pertinent to NASA's mission.

Specialized services also include creating custom thesauri, building customized databases, organizing and publishing research results.

For more information about the NASA STI program, see the following:

- Access the NASA STI program home page at http://www.sti.nasa.gov

- E-mail your question via the Internet to help@ sti.nasa.gov

- Fax your question to the NASA STI Help Desk at $443-757-5803$

- Telephone the NASA STI Help Desk at 443-757-5802

- Write to: NASA Center for AeroSpace Information (CASI) 7115 Standard Drive Hanover, MD 21076-1320 
NASA/TM—2012-217297

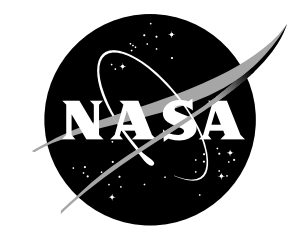

\section{Two-Dimensional Nonlinear Finite Element Analysis of CMC Microstructures}

Subodh K. Mital

The University of Toledo, Toledo, Ohio

Robert K. Goldberg and Peter J. Bonacuse

Glenn Research Center, Cleveland, Ohio

National Aeronautics and

Space Administration

Glenn Research Center

Cleveland, Ohio 44135 
Trade names and trademarks are used in this report for identification only. Their usage does not constitute an official endorsement, either expressed or implied, by the National Aeronautics and Space Administration.

This work was sponsored by the Fundamental Aeronautics Program at the NASA Glenn Research Center.

Level of Review: This material has been technically reviewed by technical management.

Available from

NASA Center for Aerospace Information 7115 Standard Drive

Hanover, MD 21076-1320
National Technical Information Service 5301 Shawnee Road Alexandria, VA 22312

Available electronically at http://www.sti.nasa.gov 


\title{
Two-Dimensional Nonlinear Finite Element Analysis of CMC Microstructures
}

\author{
Subodh K. Mital \\ The University of Toledo \\ Toledo, Ohio 43606 \\ Robert K. Goldberg and Peter J. Bonacuse \\ National Aeronautics and Space Administration \\ Glenn Research Center \\ Cleveland, Ohio 44135
}

\begin{abstract}
A research program has been developed to quantify the effects of the microstructure of a woven ceramic matrix composite and its variability on the effective properties and response of the material. In order to characterize and quantify the variations in the microstructure of a five harness satin weave, chemical vapor infiltrated (CVI) SiC/SiC composite material, specimens were serially sectioned and polished to capture images that detailed the fiber tows, matrix, and porosity. Open source quantitative image analysis tools were then used to isolate the constituents, from which two dimensional finite element models were generated which approximated the actual specimen section geometry. A simplified elastic-plastic model, wherein all stress above yield is redistributed to lower stress regions, is used to approximate the progressive damage behavior for each of the composite constituents. Finite element analyses under in-plane tensile loading were performed to examine how the variability in the local microstructure affected the macroscopic stress-strain response of the material as well as the local initiation and progression of damage. The macroscopic stress-strain response appeared to be minimally affected by the variation in local microstructure, but the locations where damage initiated and propagated appeared to be linked to specific aspects of the local microstructure.
\end{abstract}

\section{Introduction}

High temperature ceramic matrix composites (CMC) are being explored as viable candidate materials for hot section gas turbine components, airframes and other airbreathing propulsion systems that are subjected to very high temperatures. However, these materials are heterogeneous and various factors affect their properties in a specific design environment. As shown in Figure 1, (a micrograph of a five harness satin weave CVI SiC/SiC composite), the microstructure of a woven ceramic matrix composite displays a significant amount of variability and irregularity in aspects such as tow spacing, ply alignment, nesting of adjacent plies and matrix thickness. Furthermore, particularly for a CVI SiC/SiC composite, there is a significant amount of porosity that is arranged in irregular patterns. Therefore, a need exists to investigate the effects of this complex material microstructure on the effective properties and durability of these materials. A need also exists to determine how the characterized variability in the microstructure correlates with the known variability in CMC material properties.

As discussed in Nemeth, et al. (Ref. 1) and Mital, et al. (Ref. 2), in many analytical approaches that have been derived to model the response of woven ceramic matrix composites, the representative unit cell (the smallest repeating unit that is assumed to be representative of the composite as a whole) of the composite has been modeled using a "pristine", ordered architecture with average dimensions for the tow geometry and spacing. In addition, the areas between the fiber tows are assumed to be composed entirely of matrix material. The effects of porosity are accounted for by uniformly degrading the properties of the matrix based on the volume fraction of porosity in the composite. Utilizing these traditional approaches, incorrect prediction of composite properties can occur. For example, as found by Goldberg, et al. (Ref. 3), 


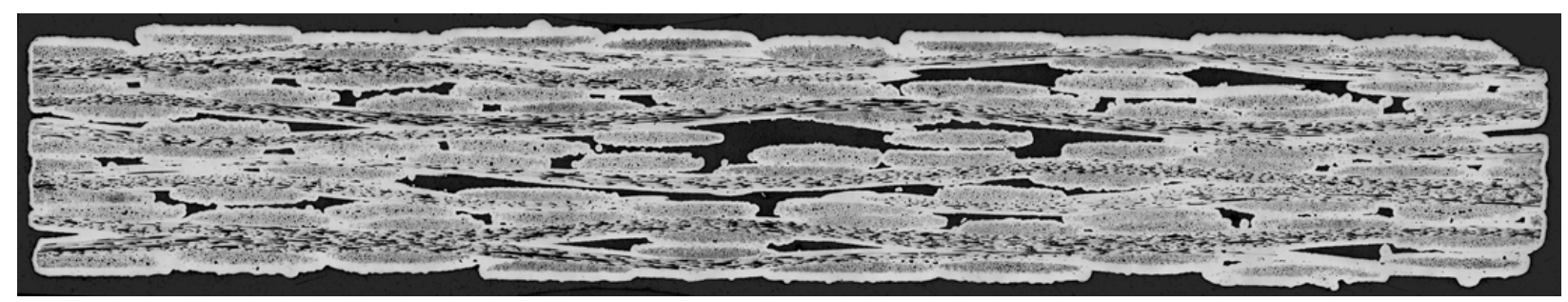

Figure 1.-Micrograph of woven SiC/SiC Composite

the through-thickness modulus has been found to be a function not only of the amount of porosity, but the shape and distribution of the porosity as well. Furthermore, Goldberg, et al. (Ref. 3) found that models of woven ceramic matrix composites that included more realistic representations of the microstructure provided an improved capability to identify the sites for stress risers where damage is likely to initiate. Traditional techniques, where the porosity is merely smeared with the matrix or the fiber tows are regularly spaced, can only capture the stress distribution in an average sense as shown by Mital, et al. (Ref. 2). The goal of an ongoing project at NASA Glenn is to investigate the effects of the complex microstructure of a woven ceramic matrix composite and its variability on the effective properties and the durability of the material. Detailed analysis of these complex microstructures may provide clues for the material scientists who 'design the material' or to structural analysts and designers who 'design with the material' regarding damage initiation and damage propagation. A representative material system, specifically a five-harness satin weave architecture CVI SiC/SiC composite composed of Sylramic-iBN fibers and a SiC matrix, is analyzed. The objective is to investigate the effects of the complex microstructure on the effective mechanical properties and durability. A separate effort by the authors involves the development of methods to characterize the distributions in as-fabricated composites of various microstructural parameters such as tow width and spacing, ply nesting, ply misalignment etc. (Ref. 4) Towards that goal, a series of finite element analyses have been performed with a simple nonlinear material model. The finite element models of two-dimensional cross-sections, which were generated from serial sections of experimental specimens, are subjected to an in-plane tensile load. A few computer-generated sections (referred to as "aligned") with a more regular spacing of the fiber tows have also been analyzed. The objective of this work is to perform simple progressive damage analyses on various sections to determine the sites for damage initiation and to relate the damage patterns to the unique architectural features of the given section. Determining the correlation between the local damage patterns and the overall stress-strain response of the material was another objective of this work. In the design of components using ceramic matrix composites, the first matrix cracking stress (or proportional limit), defined as the stress level where the macro tensile stress-strain curve deviates significantly from linearity, is often a key material allowable. As a result, particular emphasis was given in this study to determining the effects of the microstructure on the initiation and growth of damage up to the point of the first matrix cracking stress. The variability in constituent material properties, while likely to be a significant contributor to the distribution in composite properties (Refs. 5 to 7), is currently not part of this investigation.

\section{Microstructural Characterization}

High resolution images of the polished cross-sections of the CVI SiC/SiC composite material were taken for the purposes of quantifying the distributions of various composite parameters such as tow shapes and sizes, the distance between tows, the size and shape of the pores, relative alignment of plies and nesting of the plies (see Fig. 1 for an example). The images were then segmented using an automated process that is based on pixel intensities and statistical techniques to isolate various composite constituents (Ref. 3). These constituents are longitudinally sectioned tows, transverse sectioned tows, pores and the SiC matrix surrounding the tows (Fig. 2). The displayed section consists of longitudinal 
(shown in blue) and transverse (shown in green) tows, CVI-matrix (shown in red) and porosity (shown as empty spaces). However, the images of the isolated composite microstructures are not amenable to the generation of finite element models for structural analysis due to the irregular shape and sizes of constituents and ply misalignment. To compensate for these irregularities, techniques were developed to generate simplified geometries from the segmented images while still maintaining relevant microstructural details. This involved several approximations including assuming a constant thickness of the longitudinal tows based on the average values obtained from segmented images, assuming the same shape and cross-sectional area for all transverse tows, assuming a sinusoidal shape for the longitudinal tows, growing the matrix uniformly around the fiber tows and slightly adjusting the position of the longitudinal and transverse tows to minimize interference. A sample of a simplified cross section is shown in Figure 3. Some 'aligned' sections (see Fig. 4 for an example), where the transverse tows were assumed to be stacked on top of each other, were also generated to be used as a baseline to contrast with the more random nature of the as-manufactured composite material. As mentioned, the above technique involves some approximations that led to differences in segmented sections and simplified section idealizations. It has been observed that in actual segmented sections, the matrix deposition is nonuniform; thicker on the outside and thinner in the interior. Longitudinally sectioned tows show variation in the thickness due to their non-uniform cross-sectional area and slight misalignment of the plies with the sectioning plane. These and other assumptions lead to slight differences in the volume fractions of various constituents between the segmented and simplified images but the overall nature of the distribution is captured. Most importantly, simplified images can be used to generate finite element models for structural analysis as explained in the following section. The details of this technique are presented in Goldberg, et al. (Ref. 3).

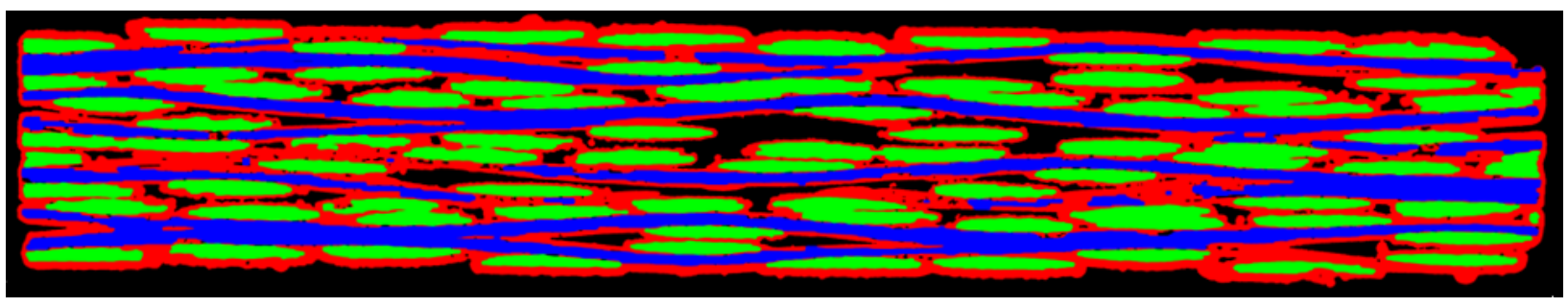

Figure 2.- Segmented image of SiC/SiC cross section including matrix (red), transverse tows (green) and longitudinal tows (blue).

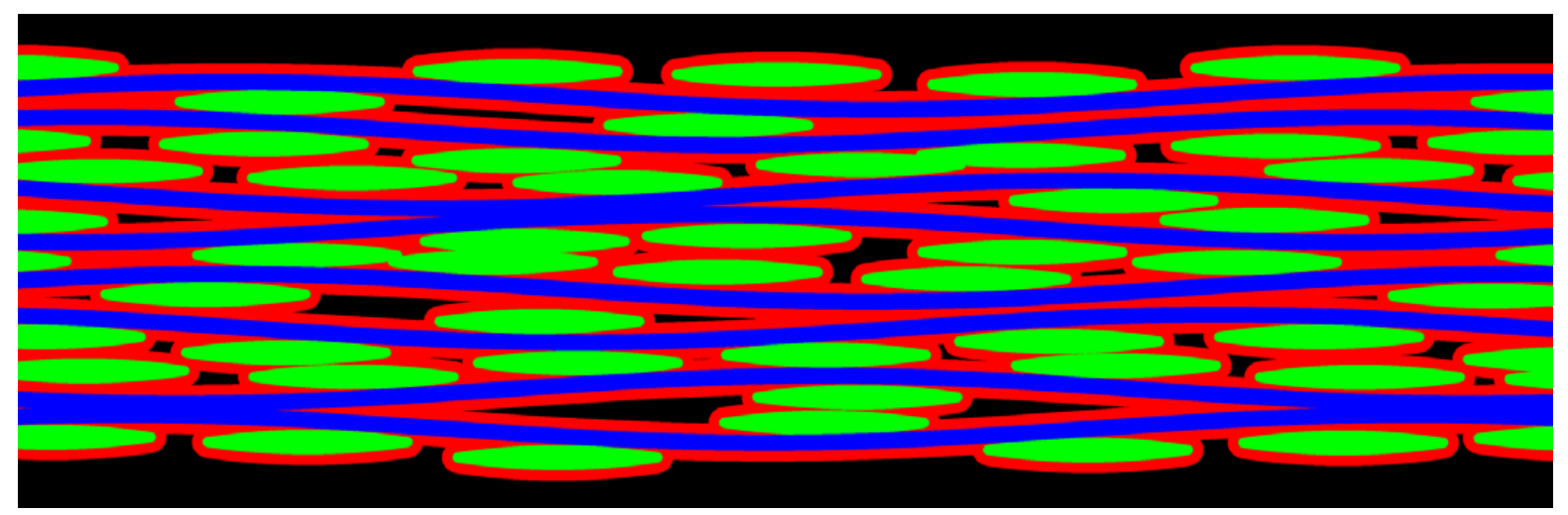

Figure 3.- "Simplified" image of SiC/SiC cross section with matrix (red), transverse tow (green) and longitudinal tow (blue) constituents. 


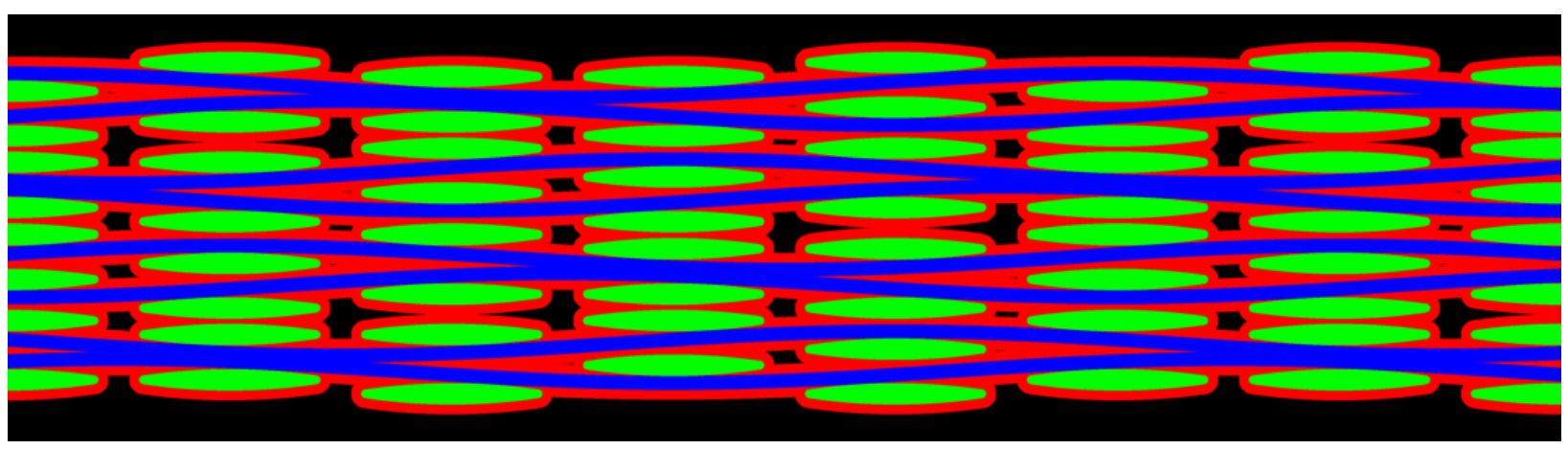

Figure 4.-_"Simplified" image of an artificially generated "aligned" cross-section.

\section{Finite Element Analysis: Results}

A software tool called OOF2 (Object Oriented Finite Element Analysis of Material Microstructures) (Ref. 8) was used to generate finite element models from simplified images of the composite cross-sections. This public domain software, running on any computer with a variant of the UNIX operating system, can export the finite element meshes directly into the ABAQUS general purpose finite element program (Ref. 9). ABAQUS can then be used to analyze the meshes for effective material properties and stress distributions. Finite element meshes were created for many actual and idealized sections. A typical finite element mesh of a representative cross-section is shown in Figure 5. As before, the displayed section consists of longitudinal (shown in blue) and transverse (shown in green) tows, CVI-matrix (shown in red) and porosity (shown as empty spaces). The longitudinal and transverse tows were treated as homogenized materials in this model even though the tow consisted of fiber, interfacial coating, matrix and intra-tow porosity. Since this intra-tow porosity has been found to be relatively uniformly distributed (Ref. 3), this porosity was not explicitly modeled but was used in determining the homogenized properties of the tow material. In a previous report, the effective in-plane and through-thickness modulus of various crosssections as well as stress distributions in these sections due to an applied in-plane tensile load were computed (Ref. 3). The idea of these analyses, performed in the linear elastic regime, was to identify the patterns of stress distribution, identify the areas of stress risers and to determine if any correlation could be found between the stress distribution and the composite microstructure. It was observed that the in-plane modulus correlated very well with the amount of porosity in the section analyzed. Higher levels of porosity lead to lower values of in-plane composite modulus. The predicted values of the in-plane modulus only changed by a few percent for intra-tow porosity volume fractions ranging from 3.2 to 5.5 percent. The predicted values of the through-thickness modulus for the different sections show a large variation. Furthermore, the variation of the through-thickness modulus was not related to how much intra-tow porosity was present in the section, but on how the porosity was arranged. If the porosity was arranged in thin sheets, a lower value of through-thickness modulus was predicted. If the porosity was arranged in large clumps, a higher value of through-thickness modulus was predicted. In addition, the average value of the throughthickness modulus correlated well with experimentally obtained values (Ref. 10). These results differed from results obtained using classical analysis techniques, discussed in Mital, et al. (Ref. 2), in which the porosity was merely smeared in the matrix. Using the classical analysis methods, the through-thickness modulus was generally overpredicted. Since damage is likely to initiate from locations of high stresses, areas of high matrix stresses were identified and they were found to be related to the locations where transverse tows were packed closely together. High stress (relative to the respective strength) sites were also found in more closely packed transverse tows, and thus they are also potential sites for damage initiation. Damage could initiate within the transverse tows due to matrix cracking or fiber matrix debonding. It was noted by Goldberg, et al. (Ref. 3) that since the large irregularly shaped inter-tow porosity is explicitly modeled in these analyses (as opposed to degrading the matrix properties), these analyses can more accurately capture locations of high stresses and thus accurately 


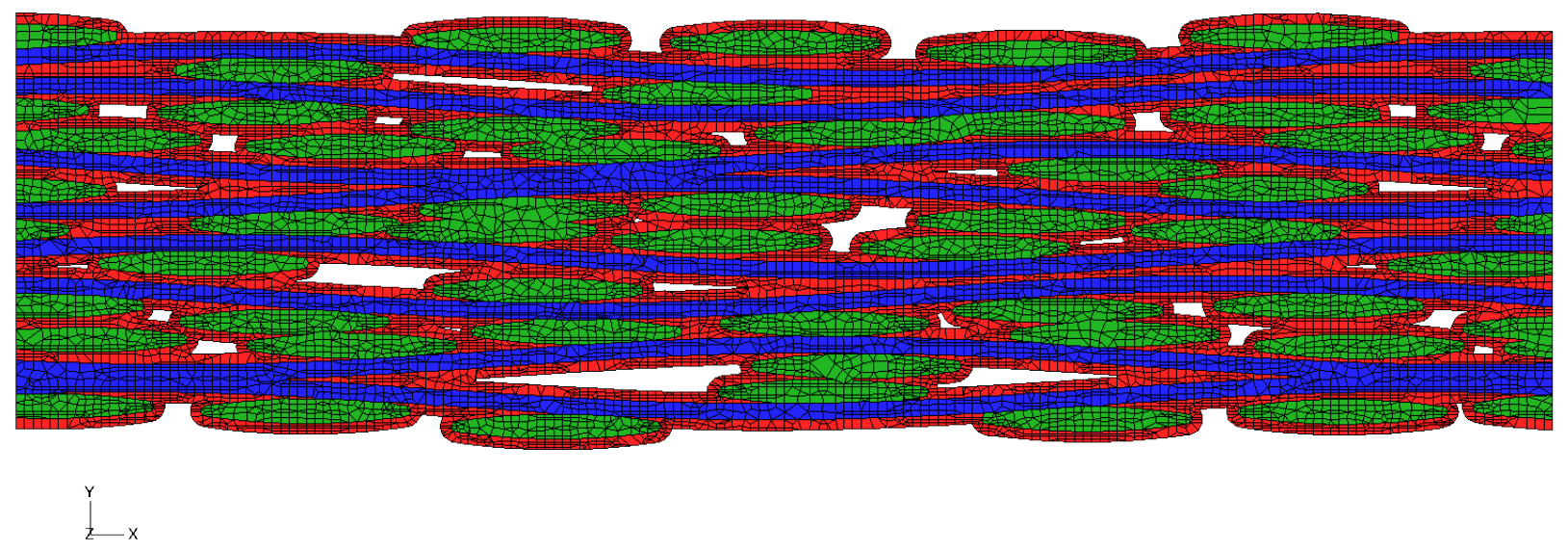

Figure 5.-Finite element mesh of a representative SiC/SiC cross section with 17442 nodes and 19502 elements (14545 linear quadrilateral and 4957 linear triangular elements).

identify sites for damage initiation. Identification of the sites of stress risers can potentially have a significant influence on the prediction of damage initiation and durability.

Following the linear elastic analyses, efforts to model the progressive damage in several sections were undertaken. The primary focus for the current study was to determine, for various actual and "aligned" sections, where damage initiated and to relate the damage locations to features of the material microstructure. The effects of the material microstructure on the progression of damage, and the state of local damage at the first matrix cracking stress (the stress level where the stress-strain curves deviates from linearity) were also a focus of the current study. To simulate the progressive damage response, several continuum damage mechanics models provided in the ABAQUS finite element program which were appropriate for ceramic composites were tried. These models are based on Hashin's damage initiation criteria and the damage evolution is based on energy dissipation. However, serious convergence issues were encountered and no credible results could be obtained. While a damage mechanics type of model would be more representative of the actual material behavior, as a first approximation an elasticperfectly plastic material model was used to analyze the initiation ('yielding') and progression of damage ('inelastic flow') in the composite. A von Mises yield surface, which allows for isotropic yield, was used for all of the composite constituents. In the future, Hill's yield surface, which allows for anisotropic yield, will be examined along with other potential anisotropic yield surfaces. However, due to the unidirectionally applied loads and the two-dimensional geometries considered in the current study, the use of an isotropic plasticity model was assumed to be acceptable. This criteria still allows for limited redistribution of stresses as the stresses above the cracking stress (here idealized as a yield stress) are redistributed to the lower stress regions. It will be shown in the following sections that even this simple damage model provides results that are in good agreement with experimental data. The emphasis in the current study, however, is not to compare different failure models but to examine the effects of different microstructural features on damage initiation and progression. A progressively increasing strain of 0.3 percent in the x-direction (in-plane direction) was applied to each section analyzed at roomtemperature. Table I shows the room-temperature elastic properties of the fiber tows and matrix used in the analysis. In this table, for the tow properties $E_{11}$ is the longitudinal modulus, $E_{22}$ is the transverse modulus, $v_{12}$ is the in-plane Poisson's ratio, and $\mathrm{G}_{12}$ is the in-plane shear modulus. For the matrix, $\mathrm{E}$ is the elastic modulus and $v$ is the Poisson's ratio. Tow properties were computed using standard micromechanics techniques for unidirectional composites (Ref. 2). In the computation of the equivalent tow properties, the porosity within the tows was assumed to be uniformly distributed within the matrix and the matrix properties were degraded to account for this intra-tow porosity. For the matrix material located outside of the tows, since the inter-tow pores were explicitly modeled, bulk matrix properties were used and no calibration or in-situ effects were modeled. 
TABLE I.-CONSTITUENT ROOM-TEMPERATURE MATERIAL PROPERTIES

\begin{tabular}{|l|l|}
\hline Tow Properties & \\
800 filament Sylramic-iBN, & $\mathrm{E}_{11}=37.7 \mathrm{Msi}(260 \mathrm{GPa})$ \\
Filament diameter $=9.5 \mu \mathrm{m}$, & $\mathrm{E}_{22}=15.3 \mathrm{Msi}(105.5 \mathrm{GPa})$ \\
BN coating thickness $=0.6 \mu \mathrm{m}, 15 \%$ porosity (assumed & $\mathrm{v}_{12}=0.18$ \\
uniformly distributed) & $\mathrm{G}_{12}=6.2 \mathrm{Msi}(42.5 \mathrm{GPa})$ \\
\hline CVI-SiC Matrix & $\mathrm{E}=61 \mathrm{Msi}(420 \mathrm{GPa})$ \\
& $v=0.2$ \\
\hline
\end{tabular}

The maximum allowable strain in the x-direction (loading direction) for each constituent was initially set as follows: 0.06 percent for matrix, 0.05 percent for the transverse tows and 0.1 percent for the longitudinal tows based on the judgment of the authors and the available constituent data. These strain values translated to a maximum allowable stress of $36.6 \mathrm{ksi}(252 \mathrm{MPa})$ for the matrix, $37.6 \mathrm{ksi}(260 \mathrm{MPa})$ for the longitudinal tows, and 7.65 Ksi (53 MPa) for the transverse tows. The yield stress for each constituent was assumed to be the failure stress or the maximum allowable stress. As mentioned earlier, on attaining the yield stress, the constituents were assumed to be perfectly plastic (i.e., the stress in the constituent remained constant at its yield stress even as the strain increased, thereby inducing local stress redistribution). In addition, the maximum allowable stresses and strains for each constituent were chosen to reflect the fact that experimental results show that the longitudinal tows fail well after the matrix and transverse tows fail. The results from the analysis of several of the actual sections (Sections 03, 1022 and 37 where the nomenclature is based on the sequence of polished sections) and two of the artificially generated "aligned" sections (Ideal-01 and Ideal-03) will be presented here. Schematics of the sections analyzed for this study are shown in Figure 6. The "aligned" sections have regularly spaced tows and a gentle undulation of longitudinal fiber tows (which is fit to the shape observed in the section micrographs) and, in general, a very regular structure.

Tensile stress-strain curves for Section 10, along with an experimentally obtained macro stress-strain curve for comparison (Ref. 6) are shown in Figure 7. It should be mentioned that the experimental data comes from test specimens that inherently contain multiple sections. Thus, the experimental data tends to homogenize the results from multiple individual sections. As can be seen in this figure, the nonlinearity of the stress-strain curve is captured by the model, and the stress and strain levels where the stress-strain curve begins to deviate from linearity coincide with the experimental results. However, the simulation predicts a flattening of the stress-strain response after the onset of nonlinearity, while the experimental results show a secondary linear region, with a steeper slope than the simulation, after the onset of nonlinearity. Even though, the results from only one section are shown in Figure 7, as will be discussed in detail later, the computed results from other sections were similar. For example, the range of proportional limit stress for various sections analyzed is 18 to $19 \mathrm{ksi}$.

In order to gain more insight into features of the macroscopic stress-strain response, a study was undertaken to evaluate the effects and sensitivity of the maximum allowable strain on the overall stressstrain behavior of the composite. The maximum allowable strain of the matrix, longitudinal tows and transverse tows were changed by \pm 25 percent from the baseline values to evaluate their sensitivity in the overall stress-strain behavior. The results from these simulations (along with an experimental curve for comparison) are shown in Figure 8. The results show that varying the matrix strength has a significant effect on the stress level where the overall stress-strain curve flattens out as expected. However, the slope of the stress-strain curve after the initial onset of nonlinearity is not significantly affected. The strength of the transverse tows has only a slight influence on the initiation of non-linearity as well as the secondary slope of the overall stress-strain curve. When the failure strain (and thus the failure strength) of the longitudinal tows is increased, the strain level at which the stress-strain curve makes its initial break from linearity does not change compared to the baseline, but the stress level at which the stress-strain curve flattens out increases. More significantly, as the longitudinal tow failure strain (and stress) is increased, the second linear region observed in the experimental results begins to appear. These results indicate that the longitudinal tow strength has a major influence on the secondary slope of the overall composite and, 


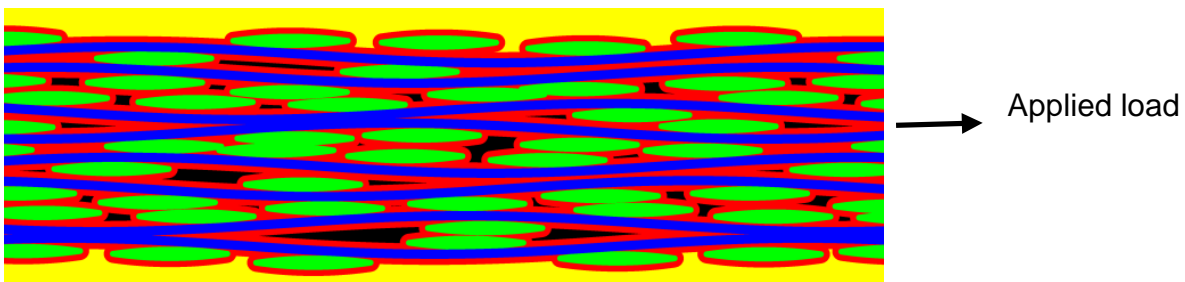

(a) Section 03

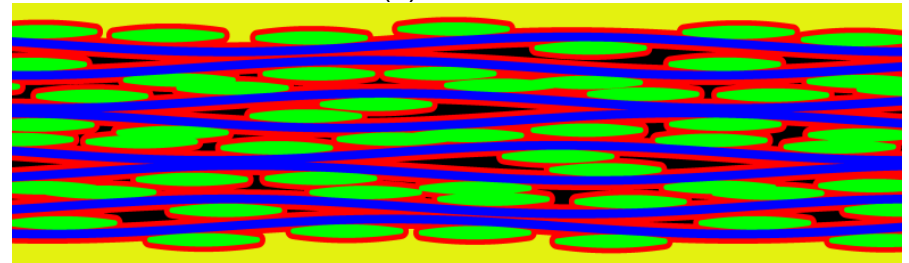

(b) Section 10

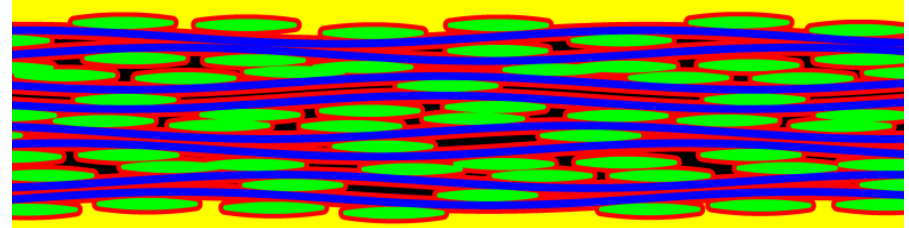

(c) Section 22

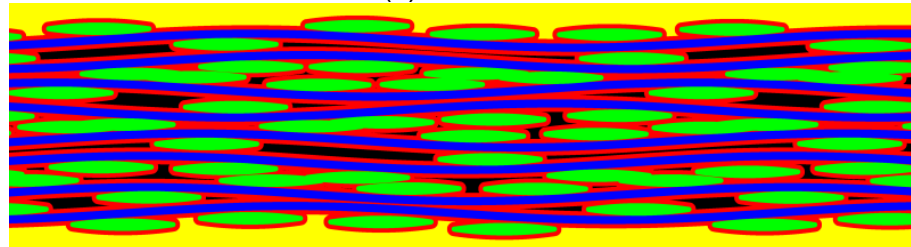

(d) Section 37

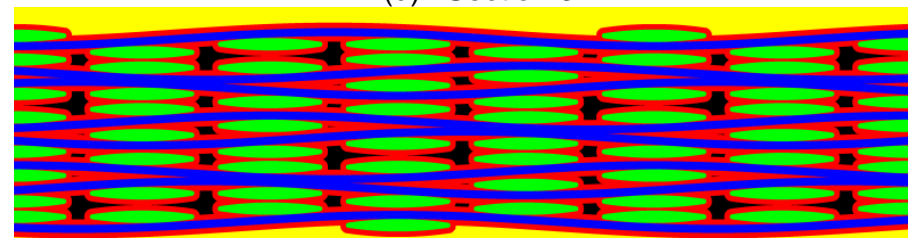

(e) Section Ideal-01

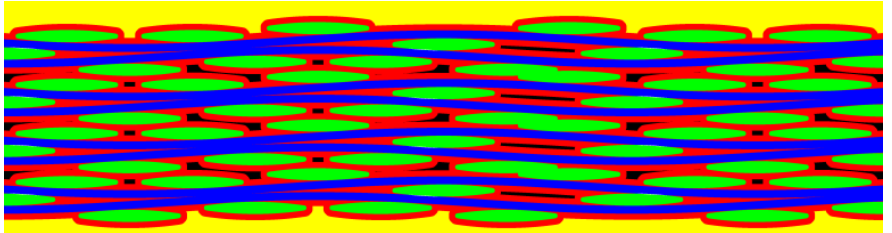

(f) Section Ideal-03

Figure 6.-Schematics of (a) Section 03, (b) Section 10

(c) Section 22, (d) Section 37, (e) Section Ideal-01 and

(f) Section Ideal-03. Longitudinal tows are shown in red, transverse tows in green, matrix is shown in red and porosity is shown as black areas. 


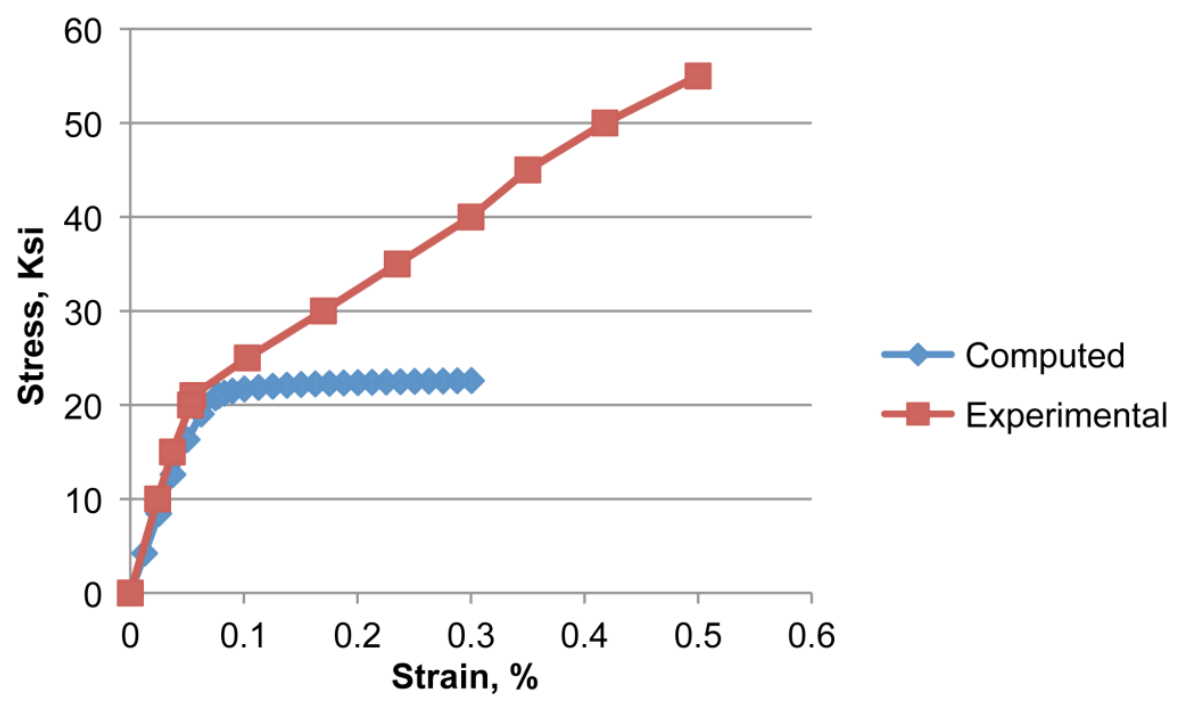

Figure 7.-Stress-strain curve of Section 10 computed using baseline constituent wstrength values with comparison to experimental results.

for the most part, controls the ultimate failure. Therefore, these results indicate that the failure strain of the longitudinal tows should be set to the overall longitudinal failure strain of the composite, 0.5 percent, with a corresponding yield/failure strength of $188 \mathrm{Ksi}$ (1300 MPa). In order to more realistically simulate the damage pattern in the composite, in the remainder of the analyses presented in this report, the longitudinal tow failure strain was adjusted to 0.5 percent.

Tensile stress-strain curves of each of the actual sections were generated using the failure strain of 0.5 percent for the longitudinal tows, and are plotted along with an experimentally obtained stress-strain curve (Ref. 11) for comparison in Figure 9, As can be seen from this figure, each of the simulated stressstrain curves for the actual sections were nearly identical, with deviations displayed only after the proportional limit. The computed stress-strain curves showed an initial linear region, and a transition to a second linear region, with a shallower slope. The transition began at a strain level of around 0.036 percent and ended at a strain level of about 0.072 percent. This shows that the damage initiates well before the first major point of macroscopic non-linearity. This has also been substantiated experimentally by using acoustic emission technique to identify damage (Ref. 12). Below the proportional limit, the computed results somewhat underpredicted the composite stress. This discrepancy is most likely due to errors in the estimated constituent properties. In particular, the constituent properties used were calibrated for another similar woven CMC system. This approximation was deemed acceptable since the emphasis in the current study was not to correlate with the experimental data. However, the stress and strain levels at which the initial nonlinearity occurs in the stress-strain response were reasonably well predicted. After the proportional limit, the analytical results appear to over predict the experimental data. This phenomenon is most likely due to the assumption that the longitudinal tows have a linear stress-strain response until failure, where in reality local matrix microcracking is likely taking place in the longitudinal tows before they fail, leading to the tows having an elastic/plastic strain hardening response, which is not accounted for in the current models. The overall character of the computed stress-strain curves matches the experimental results, however. Note that the magnitude of local stress field at a point are highly mesh sensitive and therefore should not be viewed as a quantitatively precise value. In this work, no mesh dependence study was performed to assess the sensitivity of stress values. 

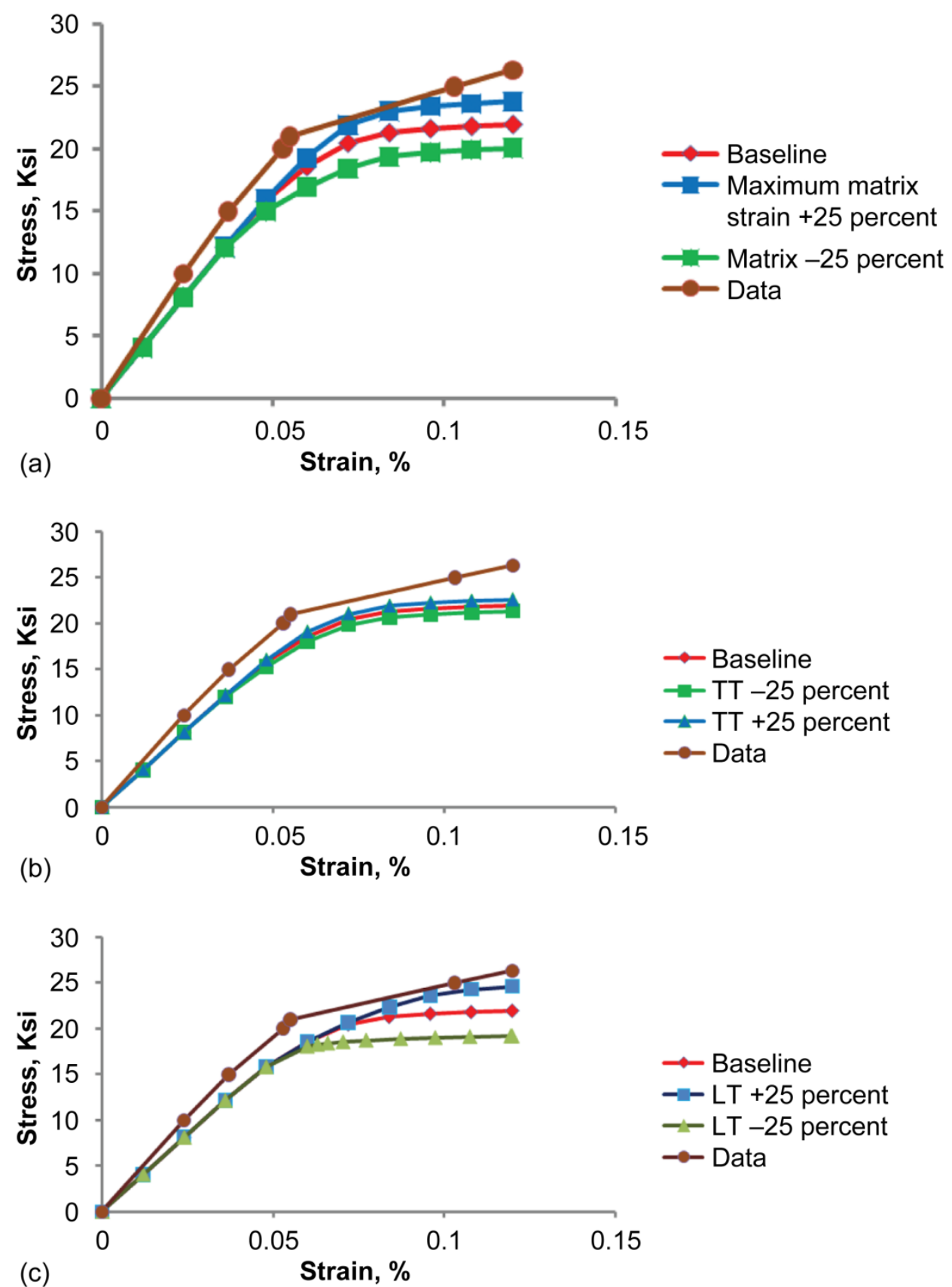

Figure 8.- Sensitivity of overall stress-strain curve to maximum allowable strain of (a) matrix, (b) transverse tows and (c) longitudinal tows for Section 10. 


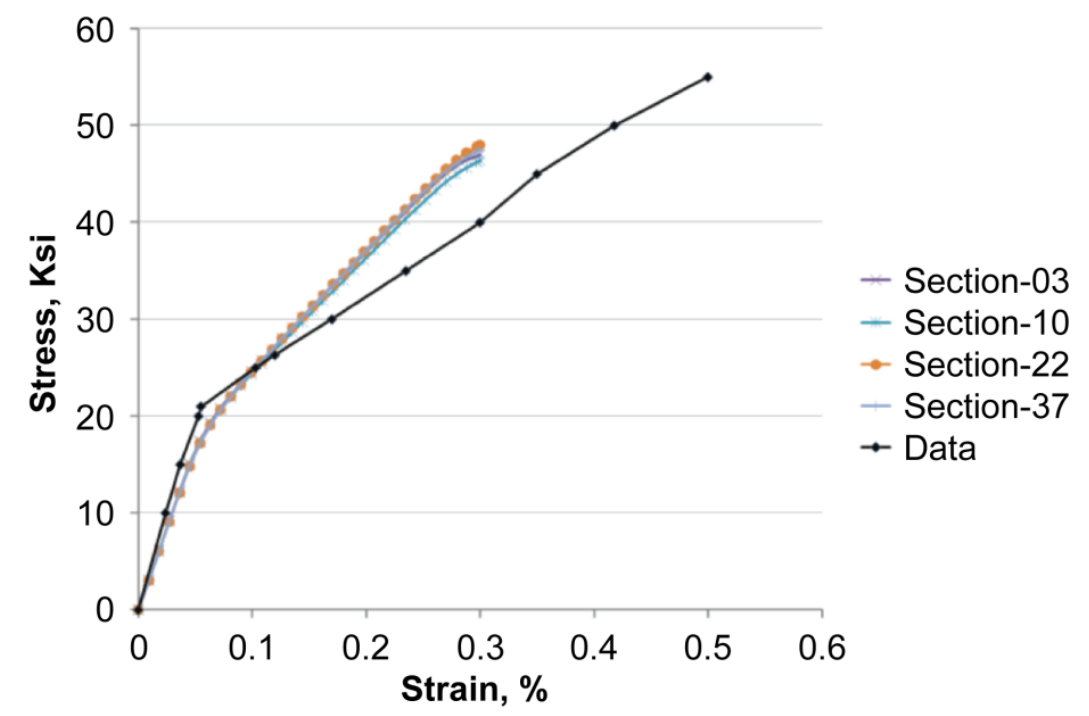

Figure 9.-Experimental and computed tensile stress-strain response of $\mathrm{SiC} / \mathrm{SiC}$ composite utilizing modified failure strains for longitudinal tows.

To better understand the local mechanisms that cause the initial nonlinearity of the macroscopic stress-strain curve, a detailed examination was conducted on the local stress levels within the examined cross-sections. The goal of the detailed examination was to obtain insights as to why sections with significantly different local architectures would yield nearly identical macroscopic response curves. The local von Mises stress levels were plotted in each of the analyzed sections at several time steps. To study the initiation and propagation of damage, several plots were generated where elements with von Mises stress levels at the specified constituent yield stress were color coded red and elements with von Mises stress levels below the specified constituent yield stress were color coded in blue. Figures 10 to 12 show the results for Section 03, Figures 13 to 15 show these results for Section 10, Figures 16 to 18 show the results for Section 22 and Figures 19 to 21 show the results for Section 37. In each of the figures, (a) shows the stresses in the transverse tows and (b) shows the stresses in the matrix. For each section, the first figure (Figs. 10, 13, 16 and 19 for example) show the local stresses at a global strain level of 0.036 percent, the second figure shows the local stresses at a global strain level of 0.054 percent, and the third figure shows the local stresses at a global strain level of 0.072 percent.

As can be seen in Figures 10, 13, 16 and 19, for each of the analyzed sections damage initiates in the transverse tows at a global strain level of 0.036 percent. For each of the sections, the initial transverse tow damage appears to take place in regions where there is a combination of two or more transverse tows touching and where there is little matrix material near the transverse tows. While the damage occurs in different relative locations within each of the cross-sections, the overall trend appears similar in each of the sections. Another point of interest is that a relatively small amount of damage ('yielding') within each section is enough to initiate nonlinearity in the overall stress-strain curve. Both the experimental and predicted stress-strain curves begin to exhibit nonlinearity at approximately this global strain level. However, the transition to nonlinearity is somewhat more gradual in the predicted curve as compared to the experimental curve. This discrepancy is most likely due to the fact that in the plasticity based material model used in the current analyses, once the yield/failure stress is reached in each constituent the stress remains at a constant level (yield stress) and sheds all additional stress to surrounding material. In the actual composite, once the constituent failure stress is reached the material starts to fail and shed load to the nearby matrix and fiber tows. Only when the damage accumulates to a critical level does the actual material behavior begin to deviate from linearity. This transverse tow unloading cannot be simulated with the current material model. Efforts are currently underway to compare the predicted damage patterns to the results obtained experimentally. This transverse tow unloading is accounted for by Liu and Arnold (Ref. 7), by modeling the tow behavior in-situ using micromechanics. 


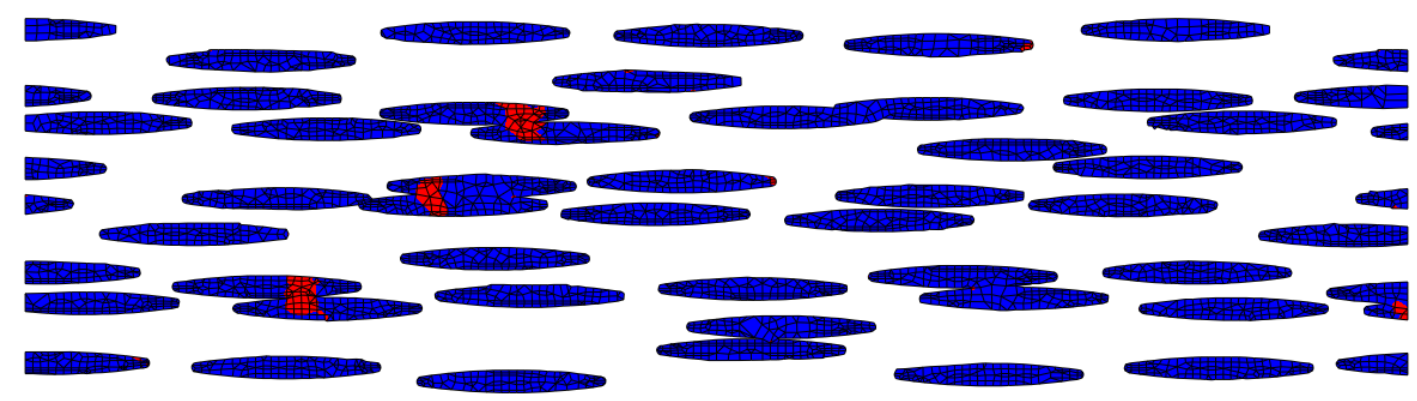

(a)

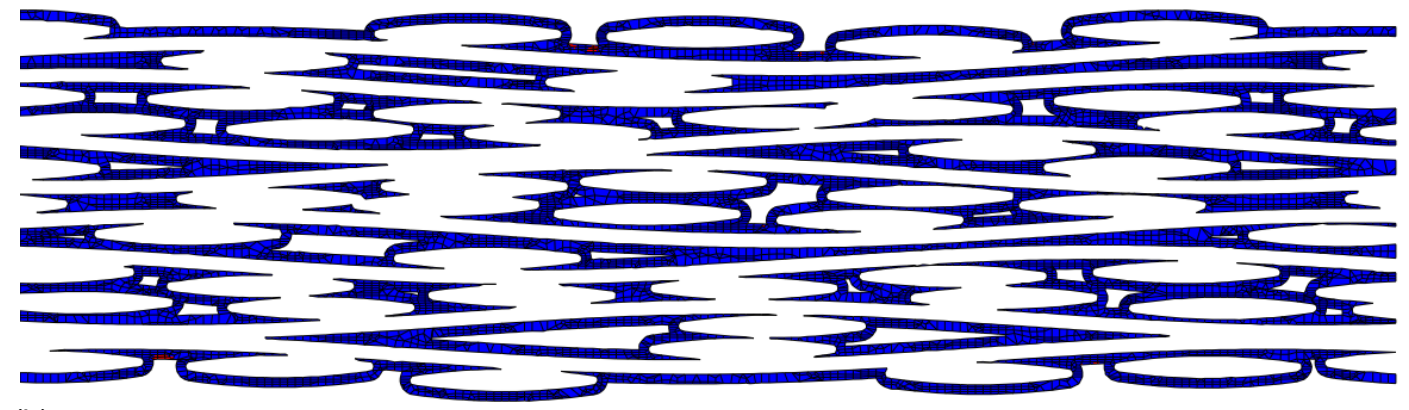

(b)

Figure 10.-Areas in (a) transverse tows and (b) matrix in Section 03 at strain level of 0.036 percent where von Mises stress is at yield (failure) indicated by red color and below yield (failure) stress indicated by blue color.

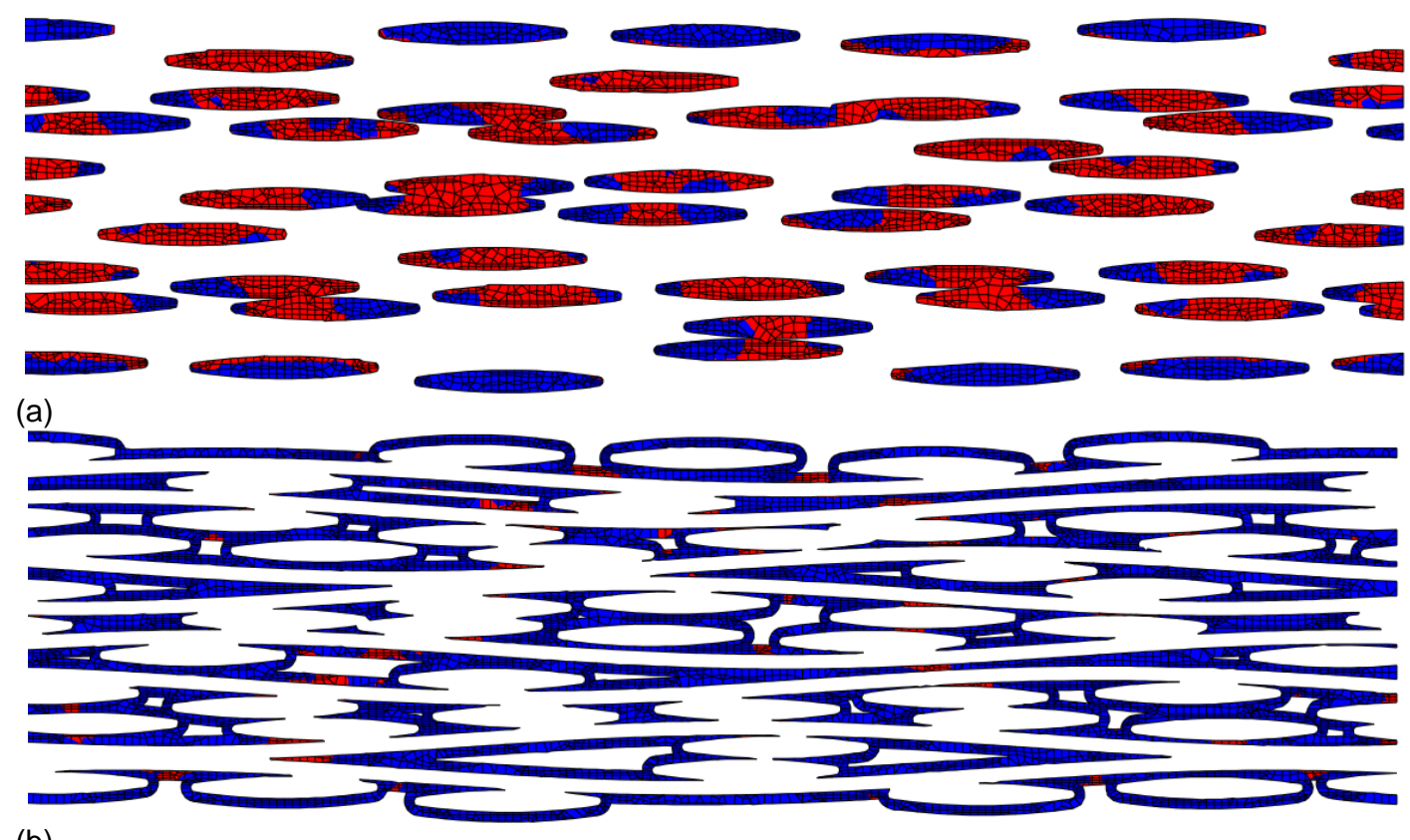

(b)

Figure 11.-Areas in (a) transverse tows and (b) matrix in Section 03 at strain level of 0.054 percent where von Mises stress is at yield (failure) indicated by red color and below yield (failure) stress indicated by blue color. 


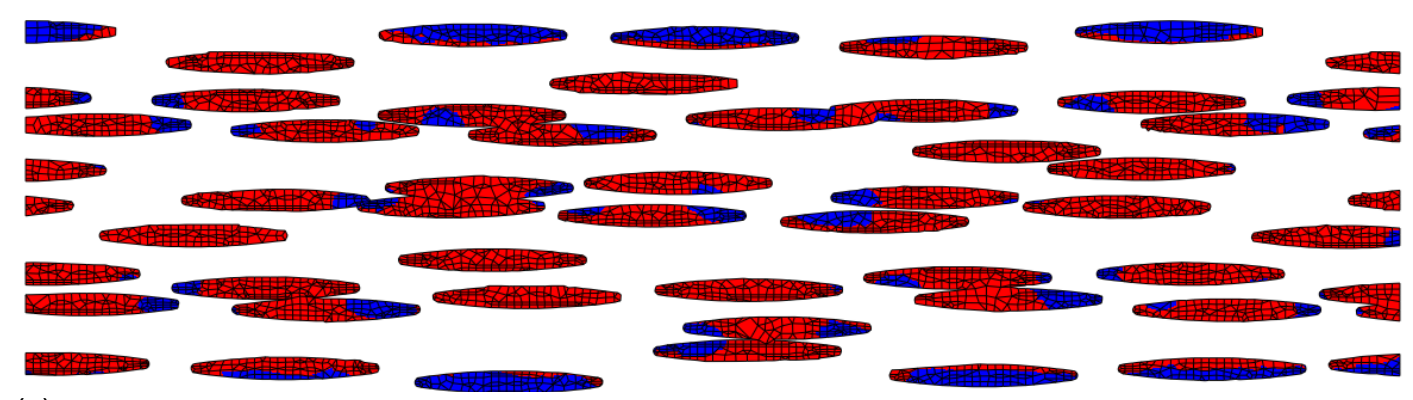

(a)

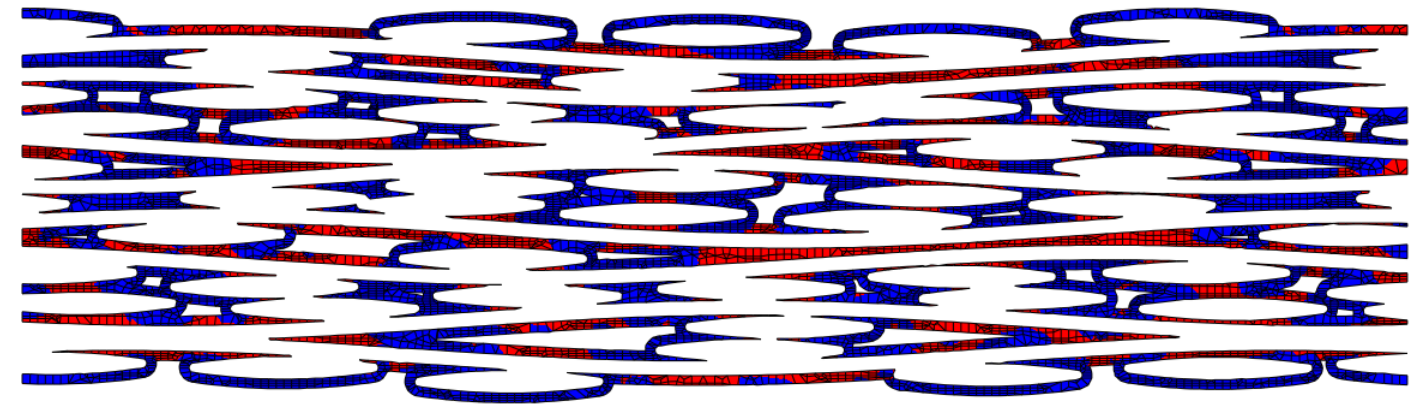

(b)

Figure 12.-Areas in (a) transverse tows and (b) matrix in Section 03 at strain level of 0.072 percent where von Mises stress is at yield (failure) indicated by red color and below yield (failure) stress indicated by blue color.

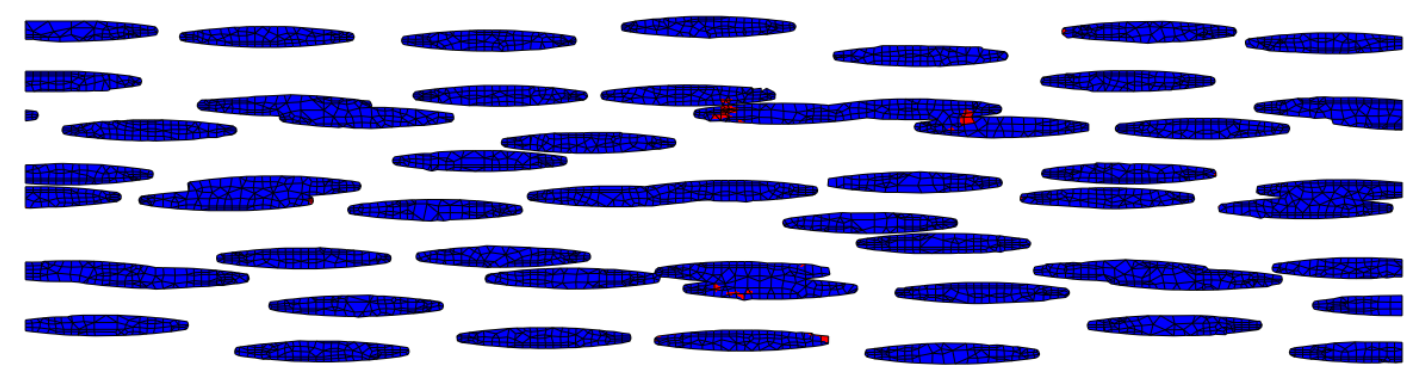

(a)

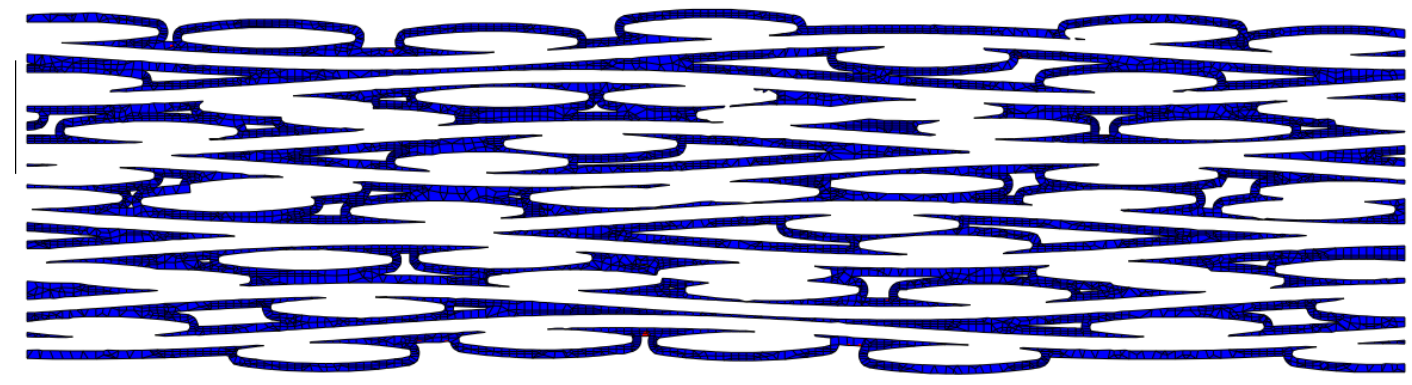

(b)

Figure 13.-Areas in (a) transverse tows and (b) matrix in Section 10 at strain level of 0.036 percent where von Mises stress is at yield (failure) indicated by red color and below yield (failure) stress indicated by blue color. 


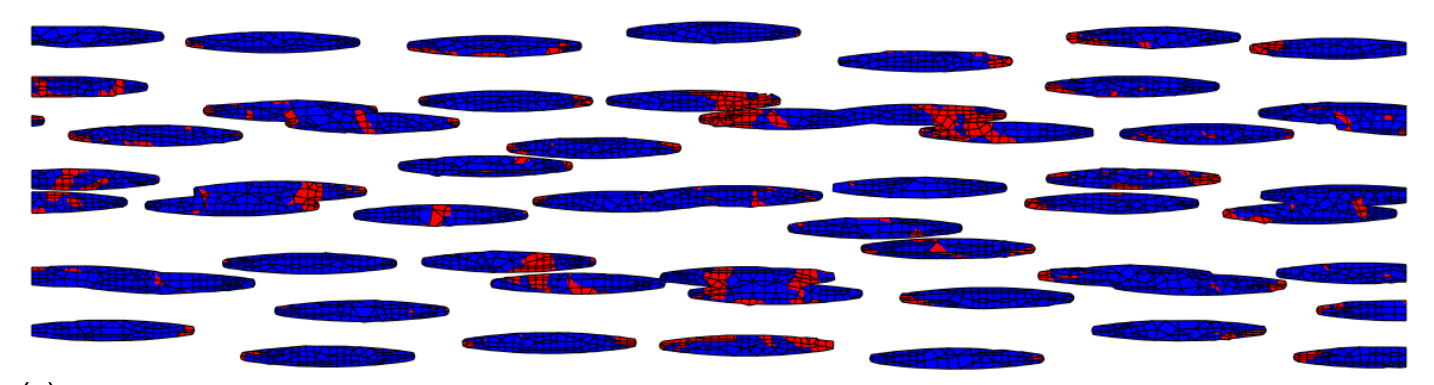

(a)

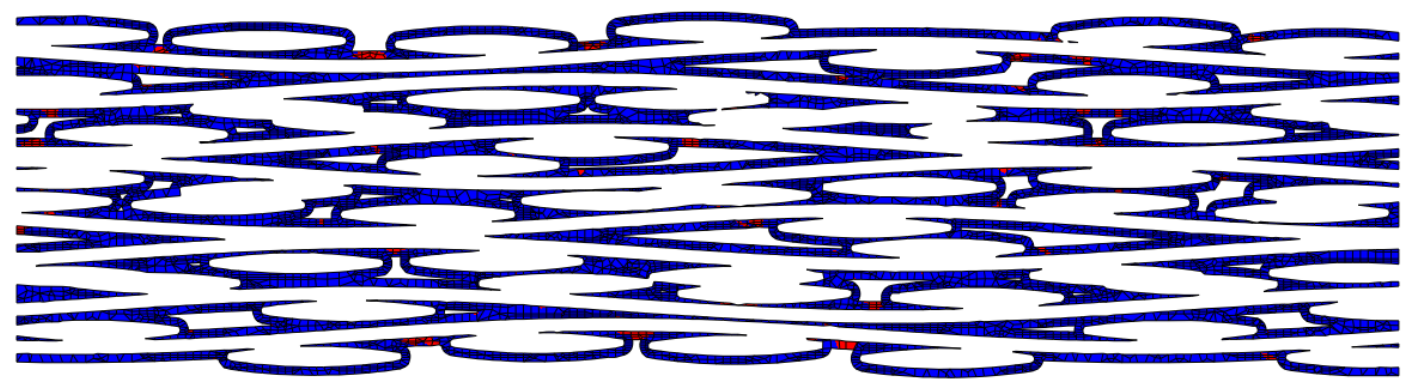

(b)

Figure 14.-Areas in (a) transverse tows and (b) matrix in Section 10 at strain level of 0.054 percent where von Mises stress is at yield (failure) indicated by red color and below yield (failure) stress indicated by blue color.

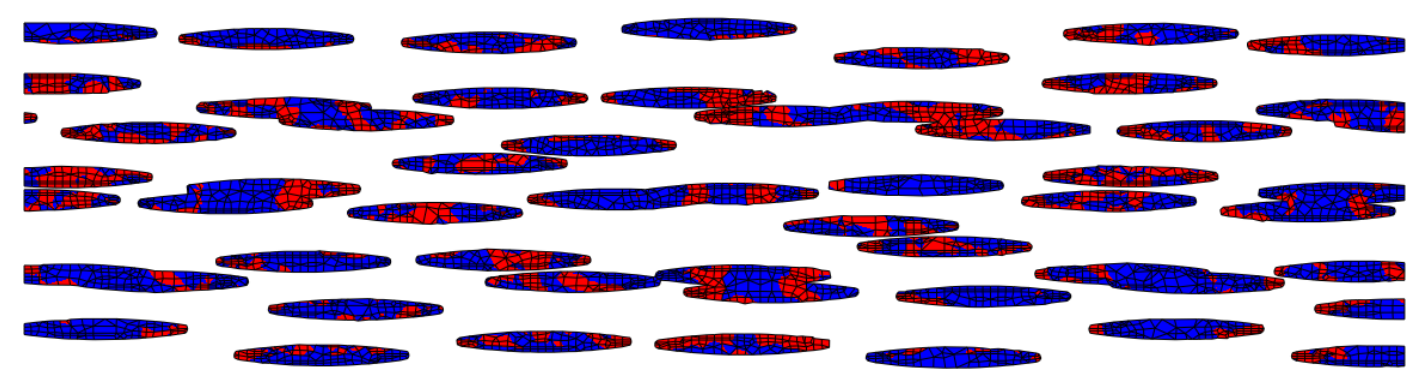

(a)

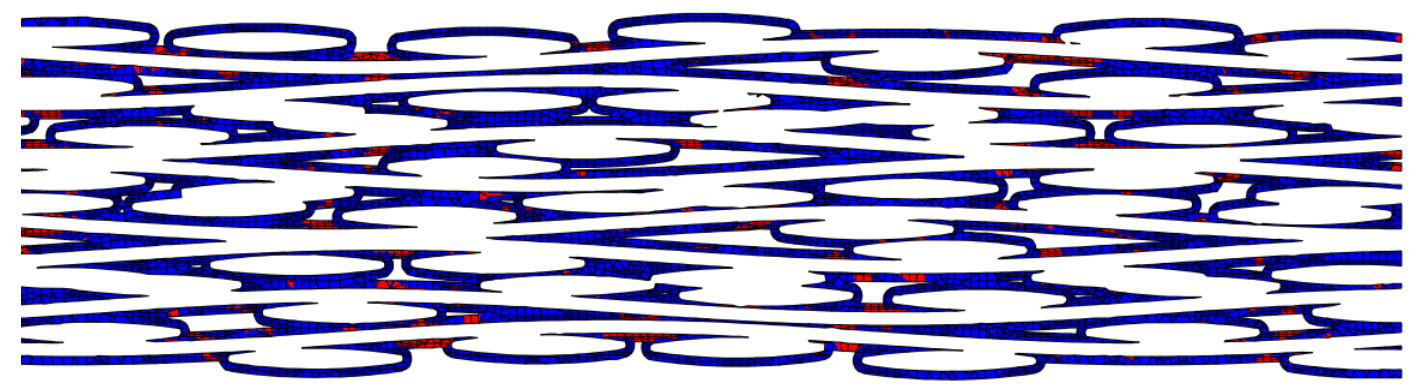

(b)

Figure 15.-Areas in (a) transverse tows and (b) matrix in Section 10 at strain level of 0.072 percent where von Mises stress is at yield (failure) indicated by red color and below yield (failure) stress indicated by blue color. 


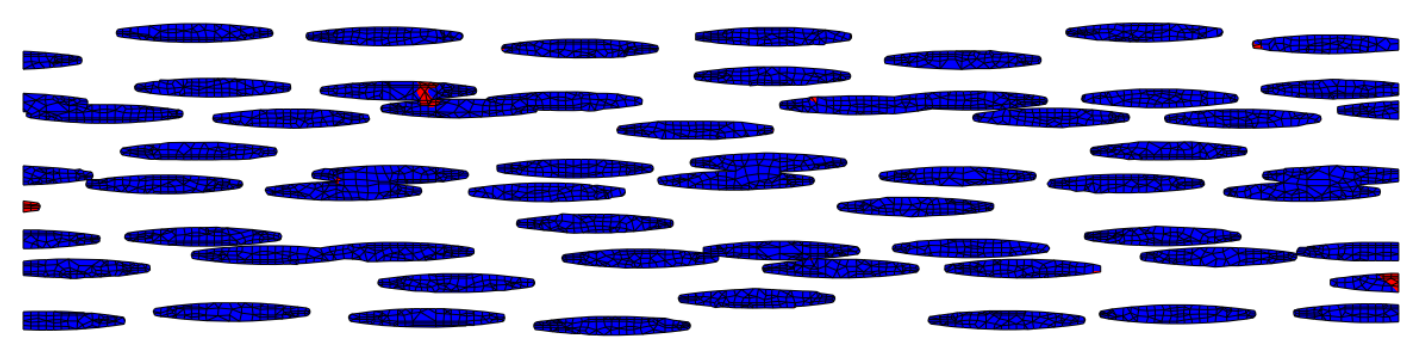

(a)

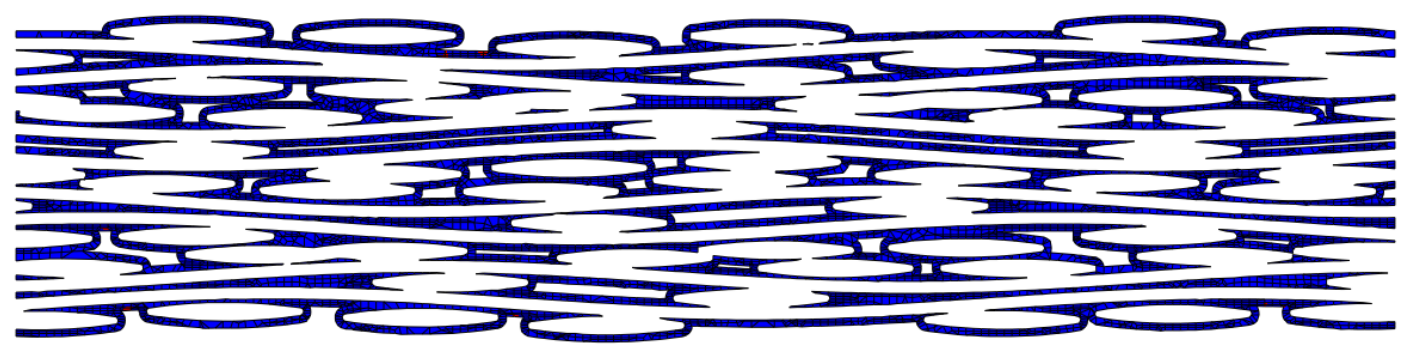

(b)

Figure 16.-Areas in (a) transverse tows and (b) matrix in Section 22 at strain level of 0.036 percent where von Mises stress is at yield (failure) indicated by red color and below yield (failure) stress indicated by blue color.

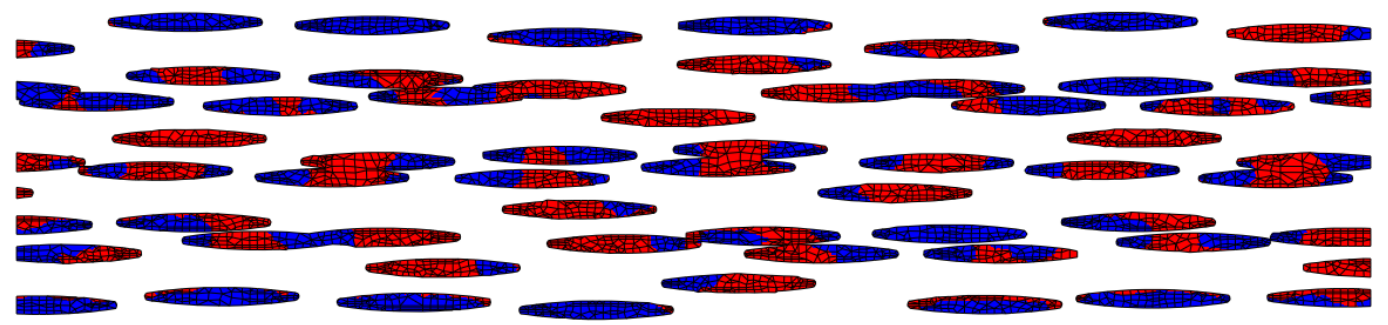

(a)

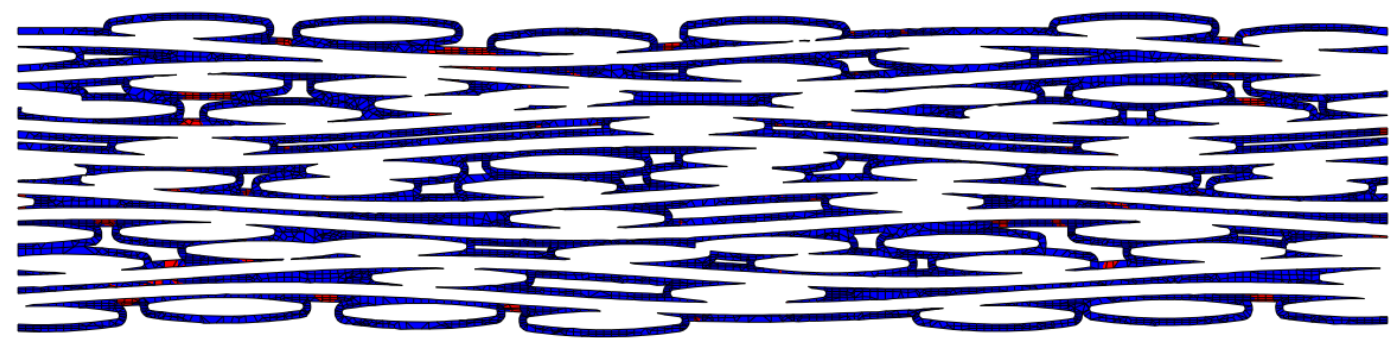

(b)

Figure 17.-Areas in (a) transverse tows and (b) matrix in Section 22 at strain level of 0.054 percent where von Mises stress is at yield (failure) indicated by red color and below yield (failure) stress indicated by blue color. 


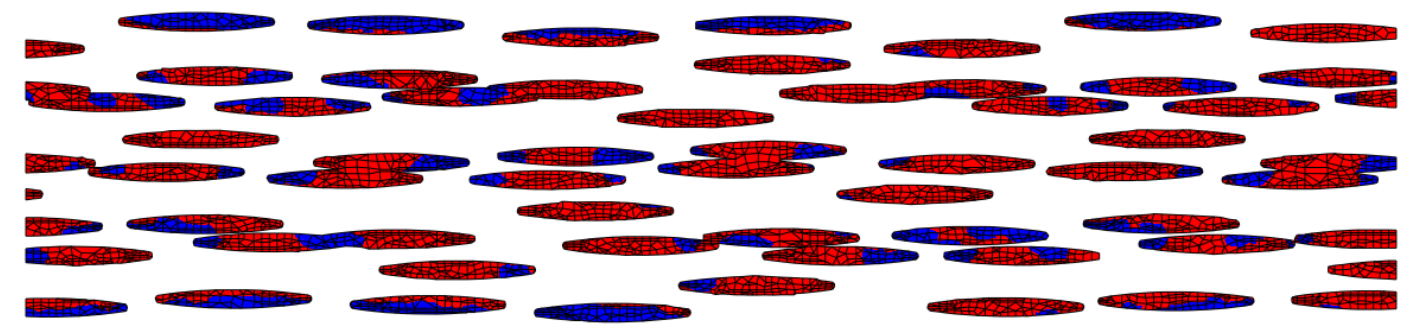

(a)

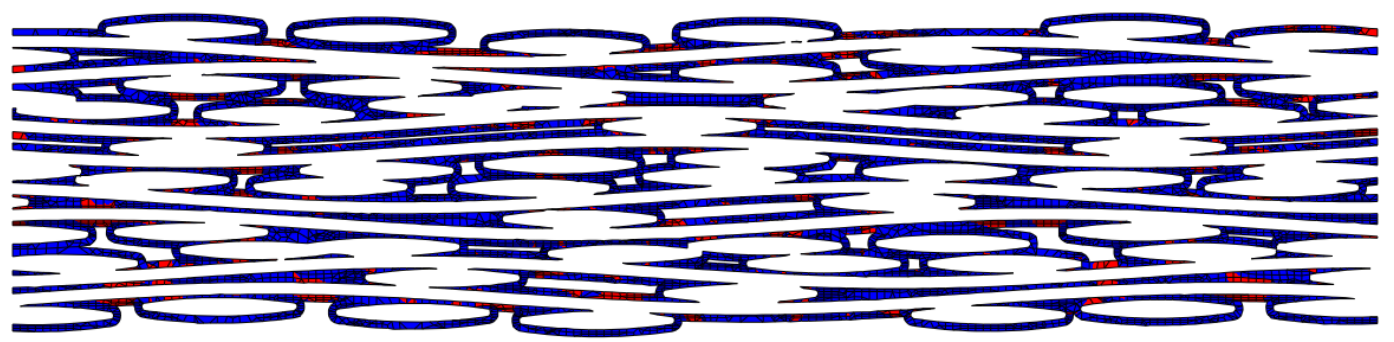

(b)

Figure 18.-Areas in (a) transverse tows and (b) matrix in Section 22 at strain level of 0.072 percent where von Mises stress is at yield (failure) indicated by red color and below yield (failure) stress indicated by blue color.

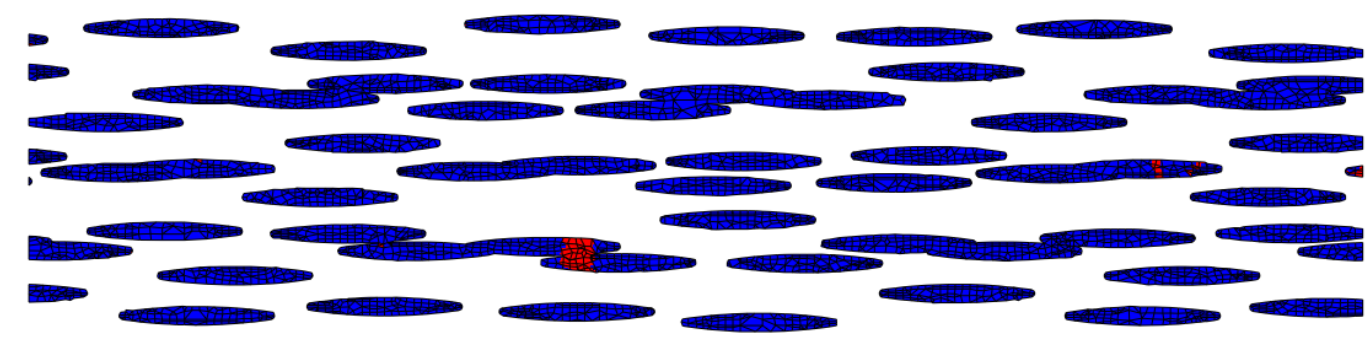

(a)

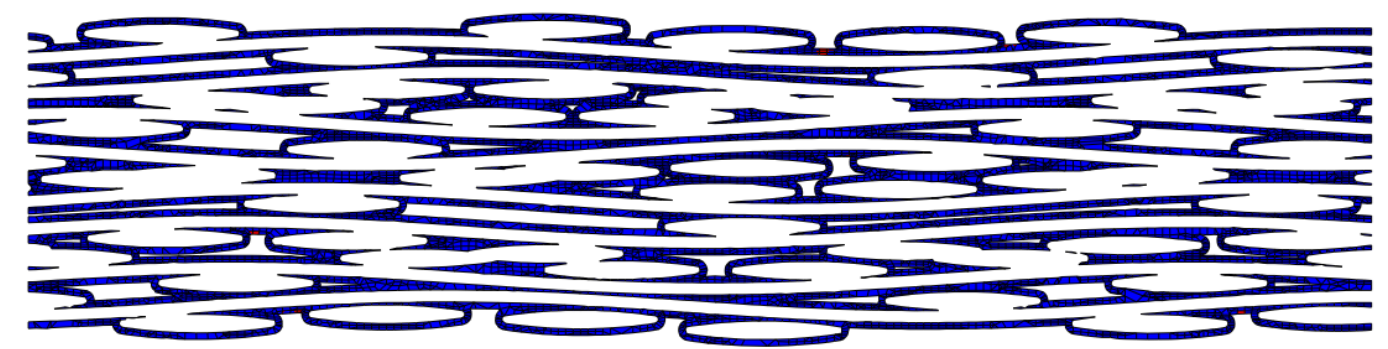

(b)

Figure 19.--Areas in (a) transverse tows and (b) matrix in Section 37 at strain level of 0.036 percent where von Mises stress is at yield (failure) indicated by red color and below yield (failure) stress indicated by blue color. 


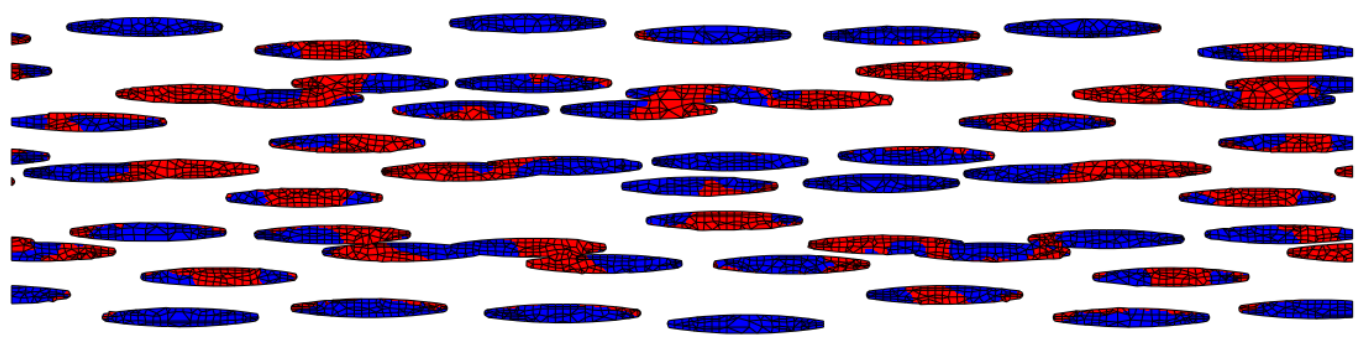

(a)

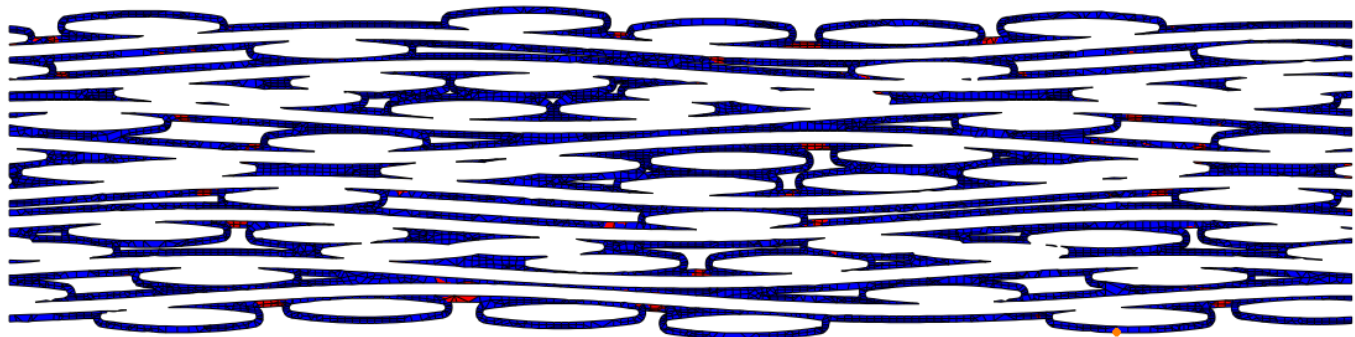

(b)

Figure 20.-Areas in (a) transverse tows and (b) matrix in Section 37 at strain level of 0.054 percent where von Mises stress is at yield (failure) indicated by red color and below yield (failure) stress indicated by blue color.

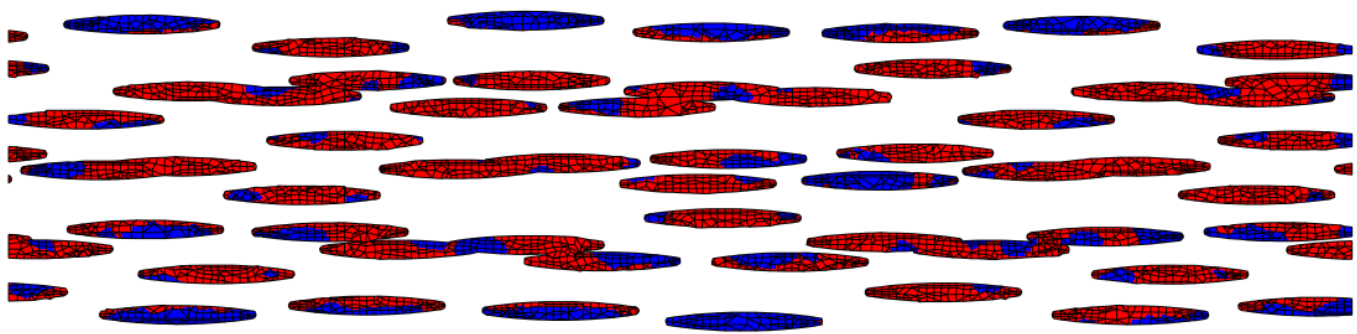

(a)

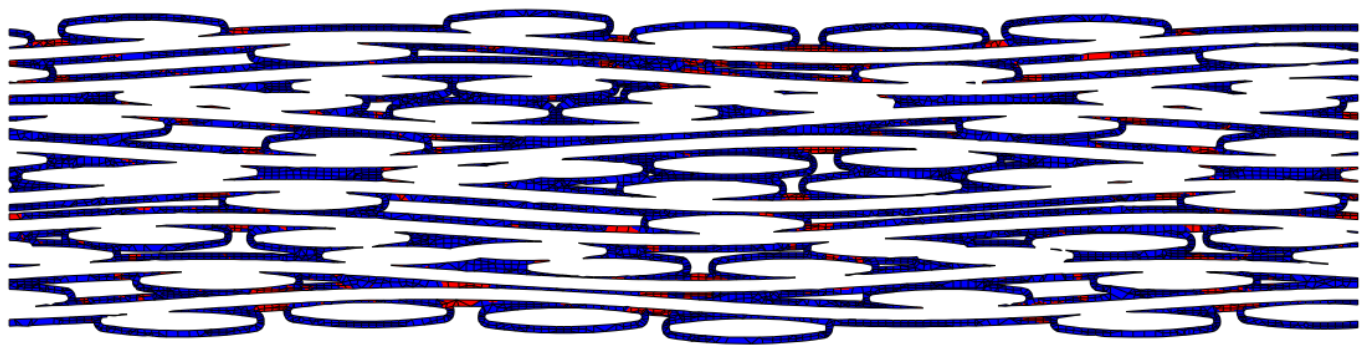

(b)

Figure 21.-Areas in (a) transverse tows and (b) matrix in Section 37 at strain level of 0.072 percent where von Mises stress is at yield (failure) indicated by red color and below yield (failure) stress indicated by blue color. 
At a global strain level of 0.054 percent, as can be seen in Figures 11, 14, 17 and 20, damage is much more widespread in the transverse tows for all of the analyzed sections. The overall level of damage in the transverse tows in Section 10 appears to be significantly less than in the other sections, for reasons which are still under investigation. In addition, at this strain level a substantial amount of damage can be observed in the matrix. On the top and bottom surfaces of each section, the matrix damage appears to be concentrated in areas between transverse tows where the tows are separated by some critical distance. In the interior of the sections, the matrix damage ('yielding') appears adjacent to areas of large pores, and near damaged transverse tows. In addition, the areas of matrix damage appear to make vertical bands through the cross-section. At 0.054 percent strain, the predicted stress-strain curve displays a significant amount of nonlinearity. These results appear to indicate that the damage in the transverse tows is a significant driver of the overall material nonlinearity. However and potentially more significantly, the results also indicate that at this strain level the combined damage in the transverse tows and the matrix form vertical bands through the thickness of the cross-section. This result indicates that a key driver of macroscopic nonlinearity is that undamaged load paths perpendicular to the loading direction start becoming unavailable. As the undamaged load paths start becoming unavailable, the overall stiffness of the material decreases.

At a global strain level of 0.072 percent, as can be seen in Figures 12, 15, 18 and 21, damage has become much more extensive. With the exception of Section 10, nearly all of the transverse tows are completely damaged. The level of damage in the matrix has also significantly increased, with Section 3 showing the most extensive amount of matrix damage. In all cases, however, multiple bands of matrix damage through the thickness of the cross-section can be observed. In the macroscopic stress-strain curve, this strain level represents the point where the second linear region of the curve begins. These results indicate that the development of transverse tow damage and a critical density of bands of damaged matrix material leads to a progressive lowering of the overall modulus reflected as nonlinearity in the macroscopic stress-strain curve, which is commonly referred to as the "first matrix cracking stress".

To gain further insight into the response of the material, two artificially generated "aligned" sections (Ideal-01 and Ideal-03) were analyzed. Figure 22 shows the tensile stress-strain curves computed for these sections, along with the results from Section 03 for comparison. Figure 22(a) shows the overall stressstrain curve, while Figure 22(b) shows a close-up of the stress-strain response up to approximately the proportional limit. The computed response of the "aligned" sections is similar in character to the response of the "actual" section, and the strain levels at which nonlinearity begins and levels off for the aligned sections are similar to the levels computed for the actual section. However, the response of Section Ideal03 is somewhat stiffer than the response of the actual sections, and the response of Section Ideal-01 is somewhat softer than the response of the actual sections. The causes for this discrepancy are still under investigation, but the discrepancies could be related to the amount and distribution of the porosity and the alignment of the transverse tows. The relative volume fractions of the various constituents could also play a role in the variation of the material response.

To further understand the local mechanisms that lead up to the initial nonlinearity of the macroscopic stress-strain curve in the aligned sections, a detailed examination of the local stress levels within the examined cross-sections was conducted. The local stress levels were again plotted in each of the analyzed sections at several composite strain levels, with elements having stress levels above the specified constituent yield stress color coded red and elements having stress levels below the specified constituent yield stress color coded blue. Figures 23 to 25 show the results for Section Ideal-01 and Figures 26 to 28 show the results for Section Ideal-03. Again, in each of the figures (a) shows the von Mises stresses in the transverse tows and (b) shows the von Mises stresses in the matrix. For each section, the first figure shows the local stresses at a global strain level of 0.045 percent (since no identifiable damage was observed at a strain level of 0.036 percent for these sections), the second figure shows the local stresses at a global strain level of 0.054 percent, and the third figure shows the local stresses at a global strain level of 0.072 percent. 


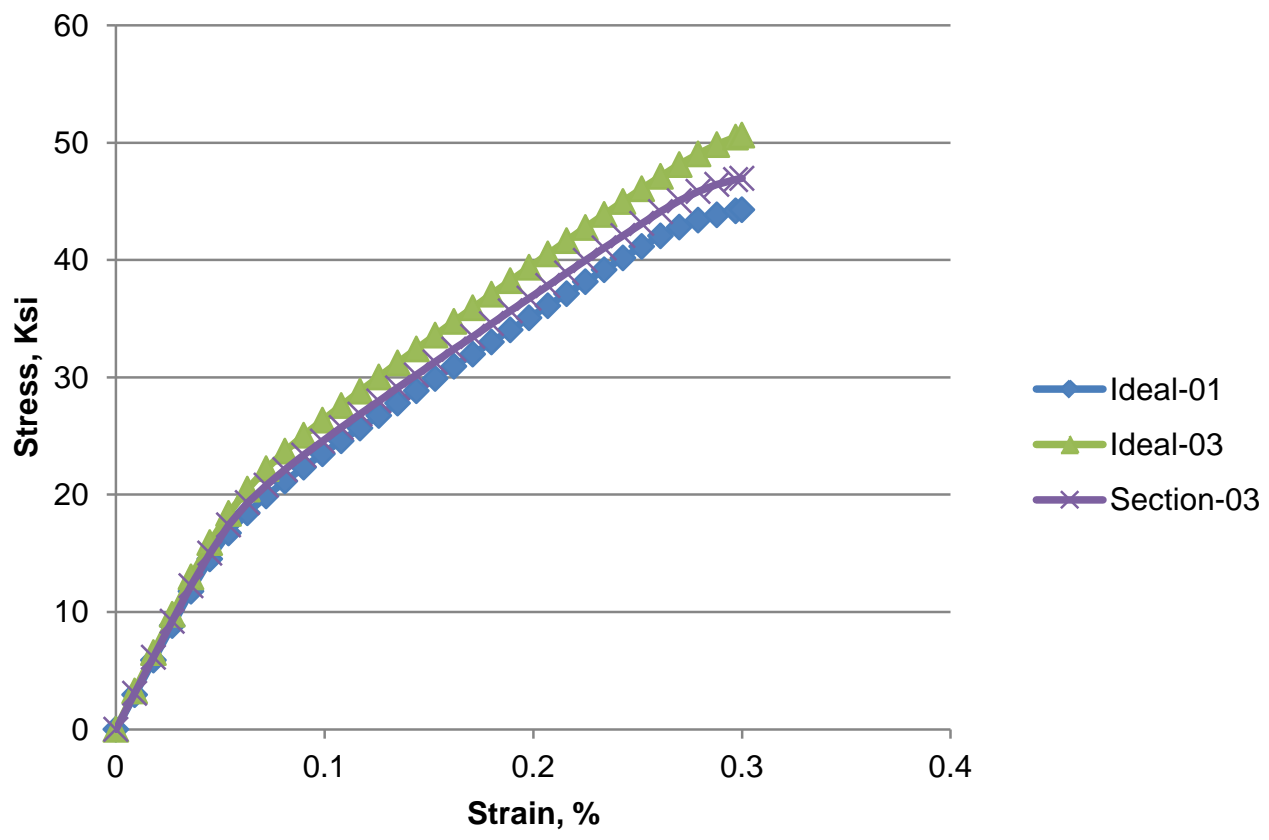

(a)

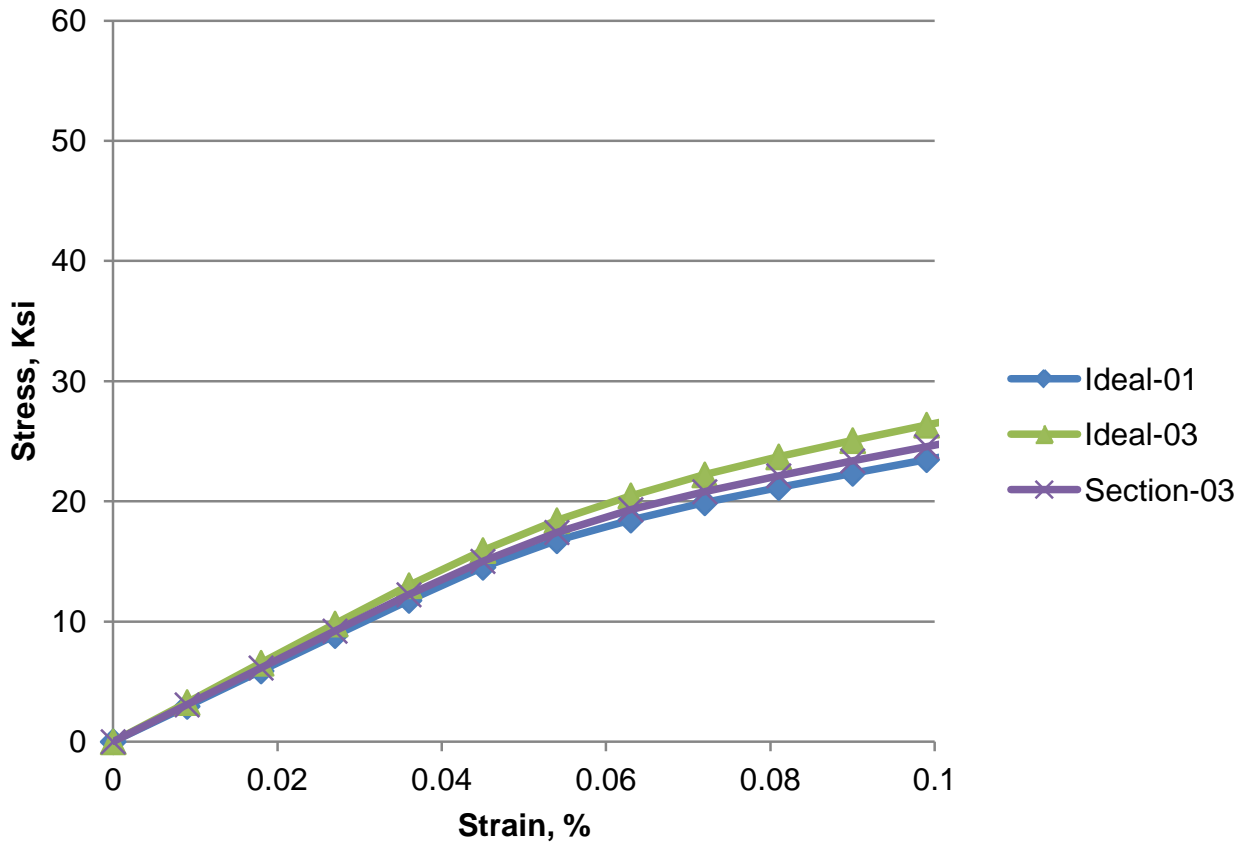

(b)

Figure 22.-Computed tensile stress-strain response of $\mathrm{SiC} / \mathrm{SiC}$ composite using idealized "aligned" cross-sections. Plot (a) shows overall response and plot (b) shows response up to proportional limit. 


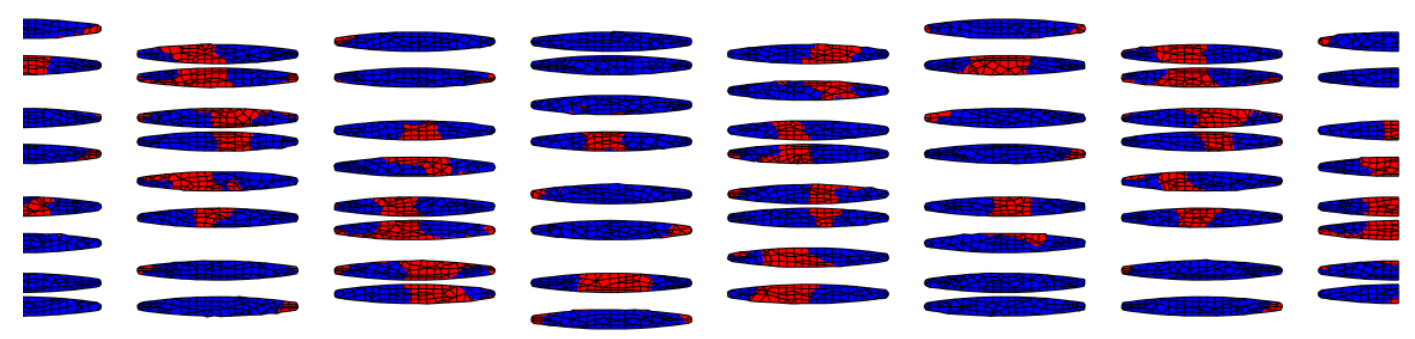

(a)

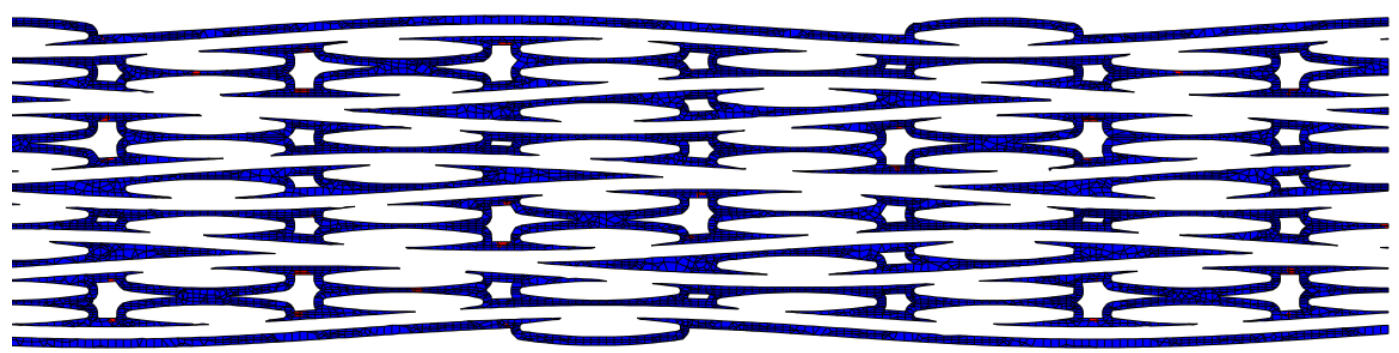

(b)

Figure 23.--Areas in (a) transverse tows and (b) matrix in Section Ideal-01 at strain level of 0.045 percent where von Mises stress is at yield (failure) indicated by red color and below yield

(failure) stress indicated by blue color.

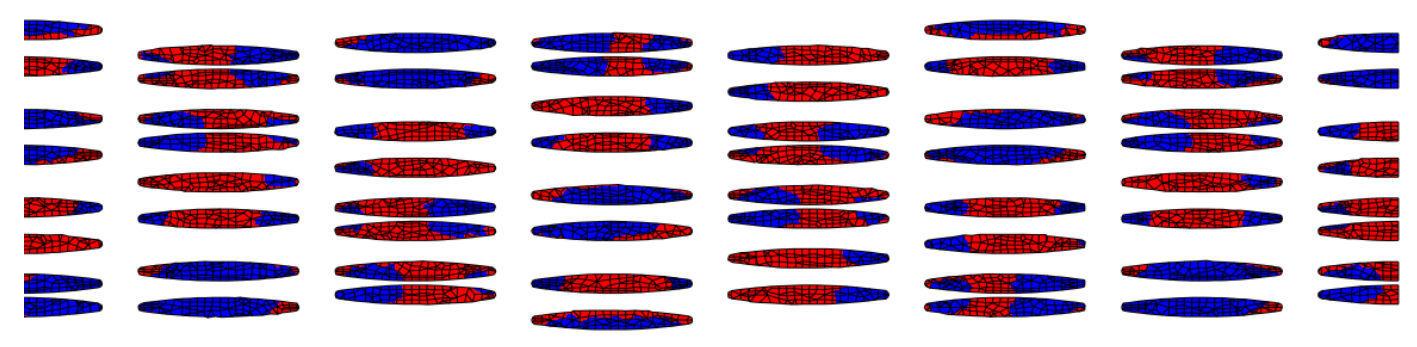

(a)

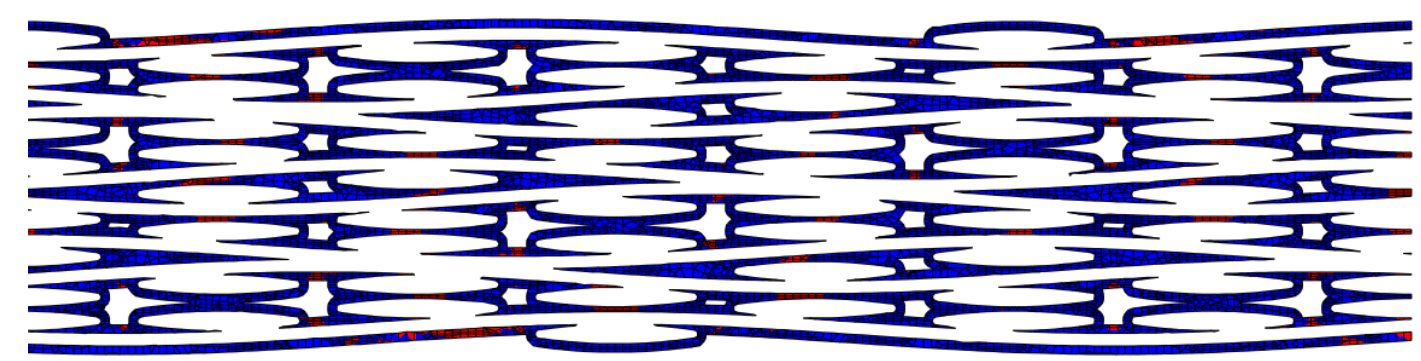

(b)

Figure 24.-Areas in (a) transverse tows and (b) matrix in Section Ideal-01 at strain level of 0.054 percent where von Mises stress is at yield (failure) indicated by red color and below yield (failure) stress indicated by blue color. 




(a)

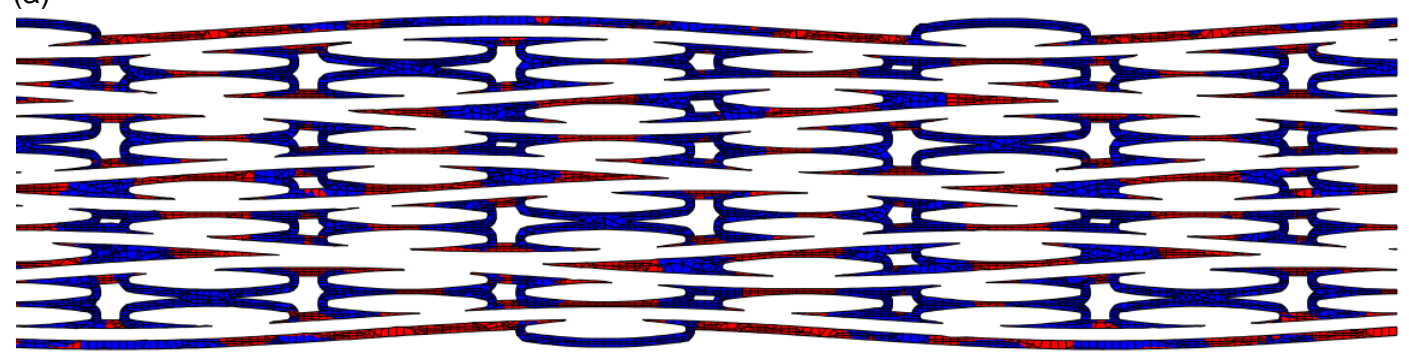

(b)

Figure 25.-Areas in (a) transverse tows and (b) matrix in Section Ideal-01 at strain level of 0.072 percent where von Mises stress is at yield (failure) indicated by red color and below yield (failure) stress indicated by blue color.

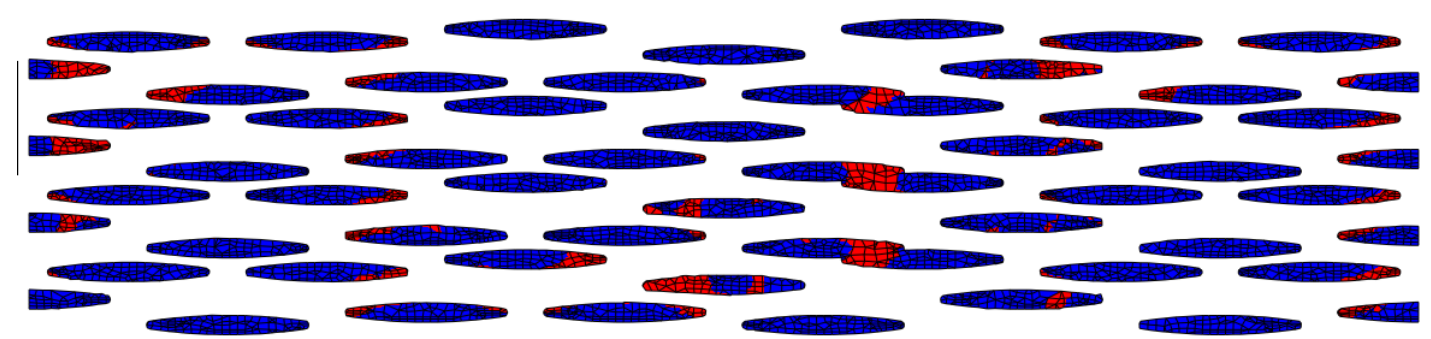

(a)

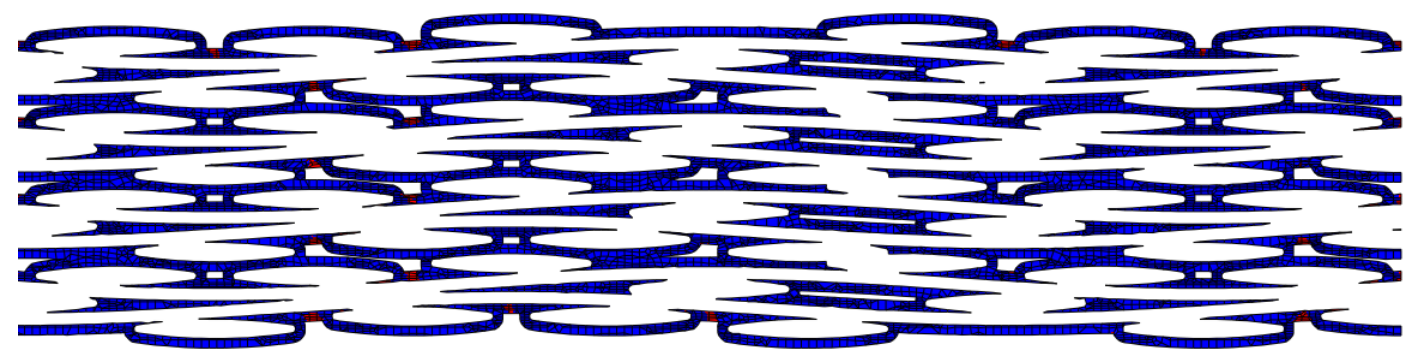

(b)

Figure 26.-Areas in (a) transverse tows and (b) matrix in Section Ideal-03 at strain level of 0.045 percent where von Mises stress is at yield (failure) indicated by red color and below yield (failure) stress indicated by blue color. 


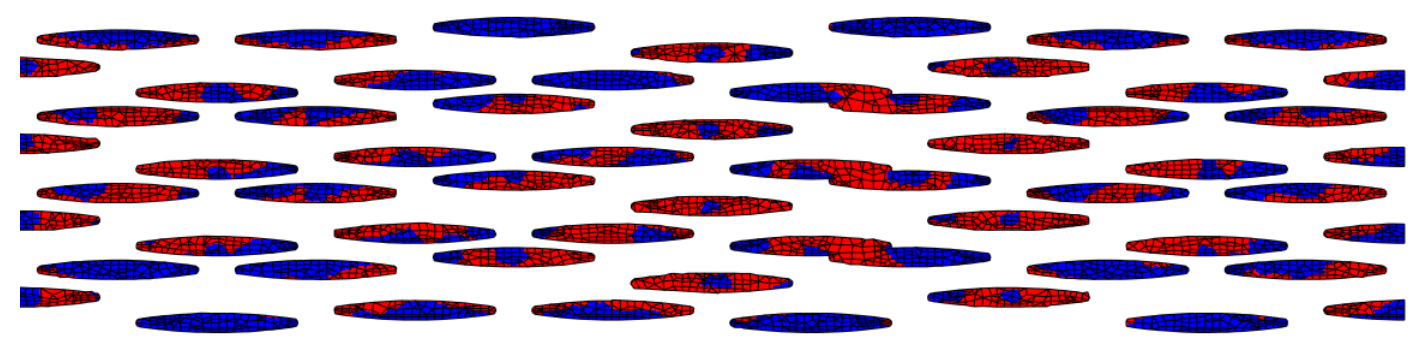

(a)

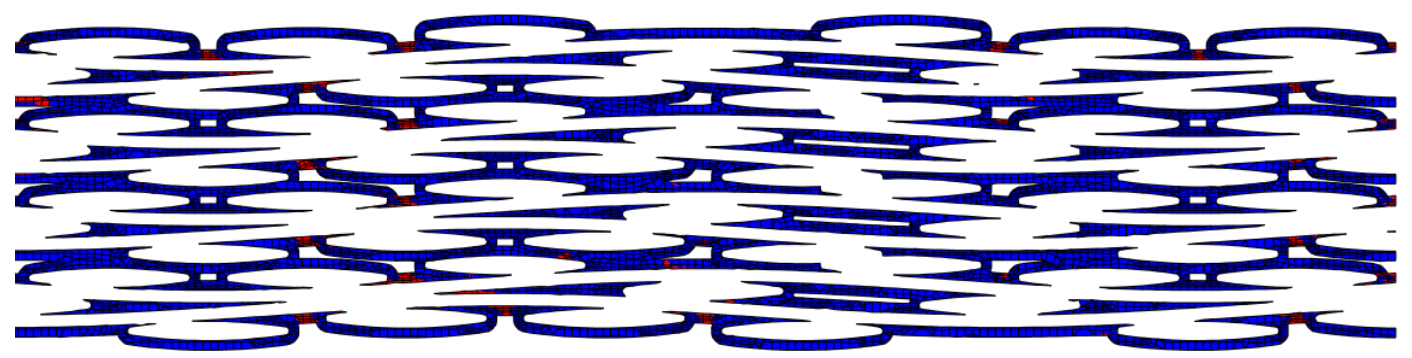

(b)

Figure 27.-Areas in (a) transverse tows and (b) matrix in Section Ideal-03 at strain level of 0.054 percent where von Mises stress is at yield (failure) indicated by red color and below yield (failure) stress indicated by blue color.

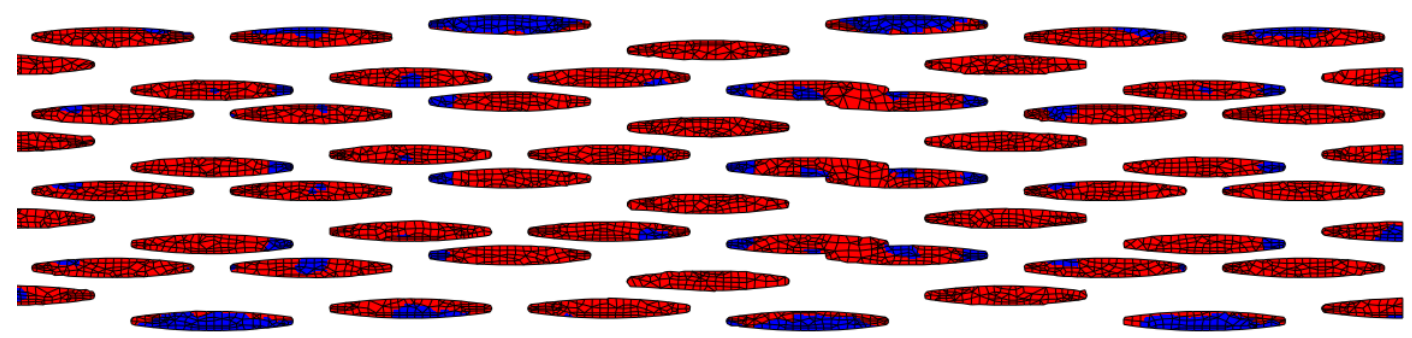

(a)

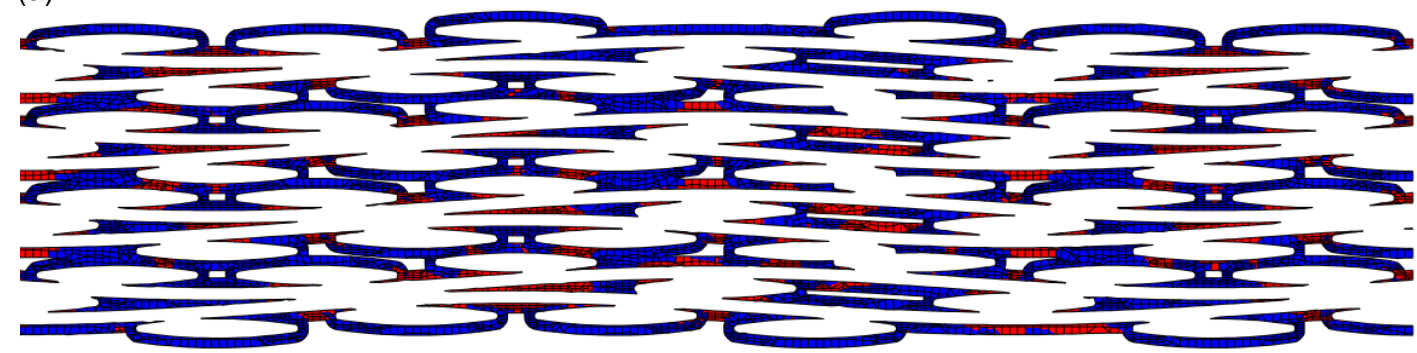

(b)

Figure 28.-Areas in (a) transverse tows and (b) matrix in Section Ideal-03 at strain level of 0.072 percent where von Mises stress is at yield (failure) indicated by red color and below yield (failure) stress indicated by blue color. 
As can be seen in Figures 23 and 26, for both of the "aligned" sections damage initiates in the transverse tows at a global strain level of 0.045 percent. For Section Ideal-01, damage initiates primarily in the transverse tows and seems concentrated in the center of the tows. Damage does not appear to be significant in transverse tows which are surrounded on both sides by large regions of porosity and have significant amounts of matrix between the transverse tows. Damage does appear to initiate in areas where the tows are tightly packed thereby excluding matrix infiltration. In Section Ideal-03, the damage appears to initiate on the edges of transverse tows near large areas of porosity, in transverse tows in regions where adjacent transverse tows touch. Matrix damage in Section Ideal-03 is present both within the large areas of porosity and the outer surfaces between transverse tows.

At a global strain level of 0.054 percent, as can be seen in Figures 24 and 27, for both of the "aligned" sections the damage is much more widespread in the transverse tows. The damage patterns in the matrix are similar to those observed in the previous strain level, with matrix damage between transverse tows becoming slightly more extensive in Section Ideal-01. These results once again indicate that transverse tow damage may be a major driving force in the nonlinearity of the macroscopic stress-strain curve.

At a global strain level of 0.072 percent, as can be seen in Figures 25 and 28, for both "aligned" sections the transverse tows have become almost completely damaged. The damage in the matrix has also become more extensive, but appears to be aligned in vertical bands across the width of the cross section. The finding that in the aligned sections damage starts in the transverse tows and progresses to vertical bands of damage in the matrix is similar to what was observed in the simplified microstructure sections. However, the detailed damage patterns in the aligned sections are different than what was observed in the simplified actual sections, for reasons that are still under investigation. As part of the process of understanding this discrepancy, detailed correlations of the initiation and progression of damage to specific features of the microstructure will be carried out in future work.

\section{Summary}

Detailed finite element analyses of a model material system, specifically a five-harness twodimensional satin weave architecture, $\mathrm{CVI} \mathrm{SiC/SiC,} \mathrm{composite} \mathrm{were} \mathrm{performed.} \mathrm{Since} \mathrm{these} \mathrm{composites}$ display significant irregularity and variability in their microstructure, this work sought to evaluate the effect of this variability on overall composite properties, damage initiation and propagation of damage, concentrating on the factors leading to the initial nonlinearity in the macroscopic stress-strain curve. The results indicate that the overall macroscopic longitudinal tensile stress-strain response of various crosssections of the composite is similar despite differences in the composition of the microstructure. The cause of this similarity may be due to the fact that for each of the sections damage was found to start in the transverse tows and progress to vertical bands of matrix damage aligned with the damage in the transverse tows. While the specific locations where these damage patterns occurred differed between the various sections, the overall pattern in the initiation and development of damage were similar. The damage initiation and progression appears to be related to the architectural and microstructural details of the sections analyzed. In this analysis, a simple damage (elastic perfectly-plastic) model was able to produce a macroscopic tensile stress-strain response that is in reasonably good agreement with the test data, along with local damage patterns that also appear to be realistic. In the in-plane direction, the macroscopic deformation behavior is very similar (as expected) and the details of microstructure have little effect. However, more realistic representations of the microstructural details provide an improved capability to identify the locations of stress risers. However, when evaluating damage initiation, caution should be used as the magnitude of the local stress value can vary significantly based on mesh density and thus the damage initiation. Future work will incorporate more realistic composite architectures, including non-uniform matrix thickness, and damage models more suitable for ceramic materials. Efforts are currently underway to compare the predicted damage patterns to the results from experimental observations. Furthermore, the effects of microstructural features on damage will be investigated in more detail and work will be conducted to quantitatively link the variability in the architecture to the material response. 


\section{References}

1. Nemeth, N.N.; Mital, S.K; and Lang, J.: "Evaluation of Solid Modeling Software for Finite Element Analysis of Woven Ceramic Matrix Composites”, NASA/TM-2010-216250, 2010.

2. Mital, S.K.; Bednarcyk, B.A; Arnold, S.M.; and Lang, J.: "Modeling of Melt-Infiltrated SiC/SiC Composite Properties”, NASA/TM-2009-215806, October 2009.

3. Goldberg, R. K.; Bonacuse, P. J.; and Mital, S. K.: "Investigation of Effects of Material Architecture on the Elastic Response of a Woven Ceramic Matrix Composite,” NASA Technical Memorandum NASA/TM-2012-217269, January 2012.

4. Bonacuse, P.J.; Mital, S.K.; and Goldberg, R.K.: "Characterization of the As Manufactured Variability in a CVI SiC/SiC Woven Composite”, Proc. of ASME Turbo Expo 2011, June 6-10, 2011, Vancouver, British Columbia, Canada.

5. Nagpal, V.K., Tong, M.T., Murthy, P.L.N. and Mital, S.K.: Probabilistic Modeling of High Temperature Material Properties of a 5-Harness 0/90 Sylramic Fiber/CVI-SiC/MI-SiC Woven Composite, NASA TM-208497, 1998.

6. Mital, S.K. and Murthy, P.L.N.: Probabilistic Micromechanical Analysis of a C/SiC Composite, NASA TM-211339, 2002.

7. Liu, K. and Arnold, S.M.: "Impact of Material and Architecture Model Parameters on the Failure of Woven CMCs via the Multiscale Generalized Method of Cells”, NASA TM in print, 2011.

8. Reid, A. et al.: "Modeling Microstructures with OOF2", Int. J. Materials and Product Technology, Vol. 35, pp. 361-373, 2009.

9. ABAQUS General Purpose Finite Element Program. Version 6.8, SIMULIA, Providence, RI

10. Morscher, G.N., Singh M., Kiser, J.D., Freedman, M., Bharr, R. "Modelling Stress-Dependent Matrix Cracking and Stress-Strain Behavior in 2D Woven SiC Fiber Reinforced CVI-SiC Composites” Composites Science and Technology, Vol. 67, 2007, pp. 1009-1017.

11. Kiser, J; Calomino, A.; Brewer, D.; DiCarlo, J.; and Morscher, G.: "SiC/SiC Composites for High Temperature Applications.” Proc. of HTCMC-7 ( $7^{\text {th }}$ International Conference on High Temperature Ceramic Matrix Composites), Sept. 19-22, 2010, Bayreuth, Bavaria, Germany.

12. Morscher, G. "Stress, Matrix Cracking, Temperature, Environment and Life of SiC/SiC Woven Composites", Proc. of HTCMC-7 ( $7^{\text {th }}$ International Conference on High Temperature Ceramic Matrix Composites), Sept. 19-22, 2010, Bayreuth, Bavaria, Germany. 


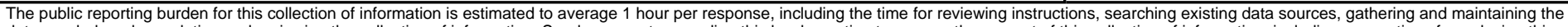

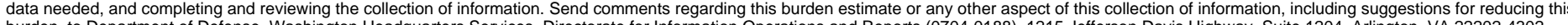

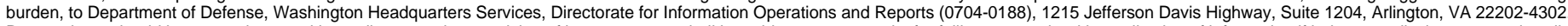

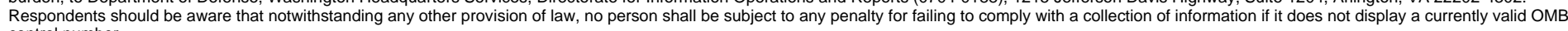

control number.
PLEASE DO NOT RETURN YOUR FORM TO THE ABOVE ADDRESS.

\begin{tabular}{l|l|l}
\hline $\begin{array}{l}\text { 1. REPORT DATE }(D D-M M-Y Y Y Y) \\
01-01-2012\end{array}$ & $\begin{array}{l}\text { 2. REPORT TYPE } \\
\text { Technical Memorandum }\end{array}$ & 3. DATES COVERED (FrOm - To)
\end{tabular}

4. TITLE AND SUBTITLE

Two-Dimensional Nonlinear Finite Element Analysis of CMC Microstructures

5a. CONTRACT NUMBER

5b. GRANT NUMBER

5c. PROGRAM ELEMENT NUMBER

6. AUTHOR(S)

Mital, Subodh, K.; Goldberg, Robert, K.; Bonacuse, Peter, J.

\section{5d. PROJECT NUMBER}

5e. TASK NUMBER

5f. WORK UNIT NUMBER

WBS 599489.02.07.03.02.11.01

7. PERFORMING ORGANIZATION NAME(S) AND ADDRESS(ES)

National Aeronautics and Space Administration

John H. Glenn Research Center at Lewis Field

Cleveland, Ohio 44135-3191

\section{SPONSORING/MONITORING AGENCY NAME(S) AND ADDRESS(ES)}

National Aeronautics and Space Administration

Washington, DC 20546-0001
8. PERFORMING ORGANIZATION REPORT NUMBER

E-18045

\section{DISTRIBUTION/AVAILABILITY STATEMENT}

Unclassified-Unlimited

Subject Categories: 24 and 39

Available electronically at http://www.sti.nasa.gov

This publication is available from the NASA Center for AeroSpace Information, 443-757-5802

\section{SUPPLEMENTARY NOTES}

\section{ABSTRACT}

A research program has been developed to quantify the effects of the microstructure of a woven ceramic matrix composite and its variability on the effective properties and response of the material. In order to characterize and quantify the variations in the microstructure of a five harness satin weave, chemical vapor infiltrated (CVI) SiC/SiC composite material, specimens were serially sectioned and polished to capture images that detailed the fiber tows, matrix, and porosity. Open source quantitative image analysis tools were then used to isolate the constituents, from which two dimensional finite element models were generated which approximated the actual specimen section geometry. A simplified elastic-plastic model, wherein all stress above yield is redistributed to lower stress regions, is used to approximate the progressive damage behavior for each of the composite constituents. Finite element analyses under in-plane tensile loading were performed to examine how the variability in the local microstructure affected the macroscopic stress-strain response of the material as well as the local initiation and progression of damage. The macroscopic stress-strain response appeared to be minimally affected by the variation in local microstructure, but the locations where damage initiated and propagated appeared to be linked to specific aspects of the local microstructure.

\section{SUBJECT TERMS}

Ceramic matrix composites; Woven composites; Finite element analysis; Microstructure; Porosity

\begin{tabular}{|c|c|c|c|c|c|}
\hline \multicolumn{3}{|c|}{ 16. SECURITY CLASSIFICATION OF: } & \multirow{2}{*}{$\begin{array}{l}\text { 17. LIMITATION OF } \\
\text { ABSTRACT } \\
\text { UU }\end{array}$} & \multirow{2}{*}{$\begin{array}{l}\text { 18. NUMBER } \\
\text { OF } \\
\text { PAGES } \\
30\end{array}$} & \multirow{2}{*}{$\begin{array}{l}\text { 19a. NAME OF RESPONSIBLE PERSON } \\
\text { STI Help Desk (email:help@sti.nasa.gov) } \\
\text { 19b. TELEPHONE NUMBER (include area code) } \\
\text { 443-757-5802 }\end{array}$} \\
\hline $\begin{array}{l}\text { a. REPORT } \\
U\end{array}$ & $\begin{array}{l}\text { b. ABSTRACT } \\
U\end{array}$ & $\begin{array}{l}\text { c. THIS } \\
\text { PAGE } \\
\text { U }\end{array}$ & & & \\
\hline
\end{tabular}



